University of Redlands

\title{
A Socially Acceptable Spatial Analysis of Utility Photovoltaic Stations
}

\author{
A Major Individual Project submitted in partial satisfaction of the requirements \\ for the degree of Master of Science in Geographic Information Systems \\ by \\ Ruben Villalpando Jr. \\ Mark Kumler, Ph.D., Committee Chair \\ Ruijin Ma, Ph.D.
}

May 2016 
A Socially Acceptable Spatial Analysis of Utility Photovoltaic Stations

Copyright (C) 2016

by

Ruben Villalpando Jr. 
The report of Ruben Villalpando Jr. is approved.

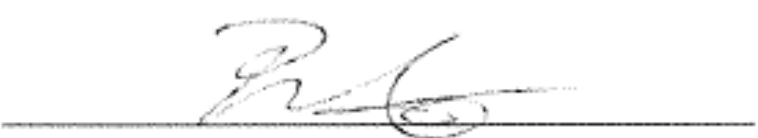

Ruijin Ma, Ph.D.

$\ln$ S.

Mark Kumler, Ph.D., Committee Chair

May 2016 



\section{Acknowledgements}

After a yearlong tour in Iraq. A platoon sergeant told us that nothing in life would compare to the hardship of war. I disagree. The path to this master's degree has been incredibly difficult. Somehow, I pulled myself through a graduate degree with severe PTSD. My own little war. The difficulty I faced seemed insurmountable. But along the way extraordinary people lend me their support, advice, and friendship. I am forever in their debt. Thank you, Dr. Willson, Dr. Kim, Sandy, Robert, Antonio, Grant, Lina, Joseph, Maruf, Matt and Luqman. Without your direct support I would not be where I am today. 



\begin{abstract}
A Socially Acceptable Spatial Analysis of Utility Photovoltaic Stations
\end{abstract}

by

Ruben Villalpando Jr.

California, with its abundant natural resources, has a long history of support for renewable energy. These efforts, however, have raised concerns in some Mojave Desert rural communities that fear such development initiatives would result in alteration of the landscape and would significantly impact their lifestyle. This study was carried out to provide rural residents with mapping visualizations that would help alleviate their concerns.

This project built a prototype tool, provided a web mapping application, and provided a three dimensional simulation. The prototype tool was developed with Esri ArcGIS software to allow the end user to adjust the relative importance of raster datasets in a suitability analysis of Utility Photovoltaic Stations. Map products derived from the tool were uploaded to ArcGIS Online to be used in a comparative analysis by means of a web mapping application. In addition, a three dimensional rendering of a utility photovoltaic station was generated to visualize how a target area may look if it were to be developed. This solution will provide rural community stakeholders with effective visualizations to determine how such efforts will affect the Mojave Desert landscape. 



\section{Table of Contents}

Chapter 1 - Introduction ......................................................................................................... 1

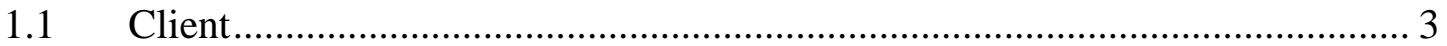

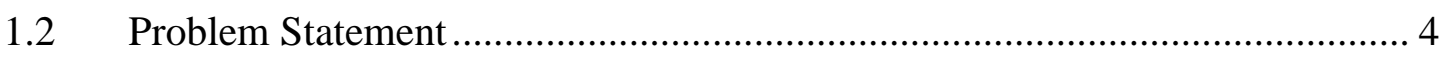

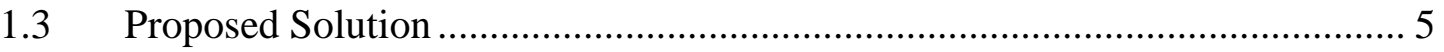

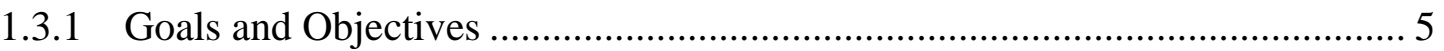

1.3.2 Scope

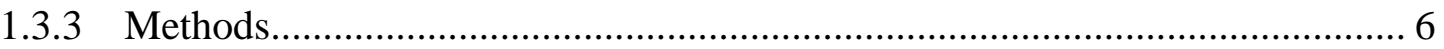

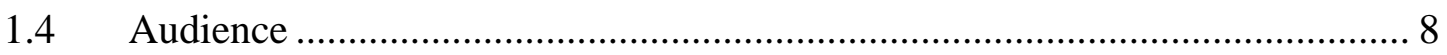

1.5 Overview of the Rest of this Report ............................................................ 8

Chapter 2 - Background and Literature Review ............................................................... 9

2.1 Suitability Methods for Utility-Scale PV Stations......................................... 12

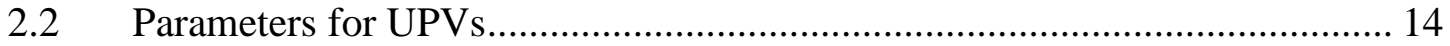

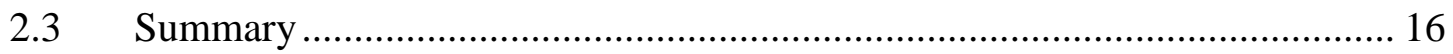

Chapter 3 - Systems Analysis and Design....................................................................... 17

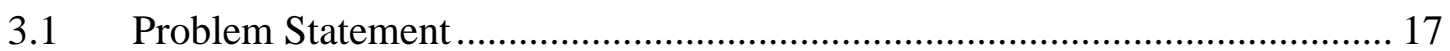

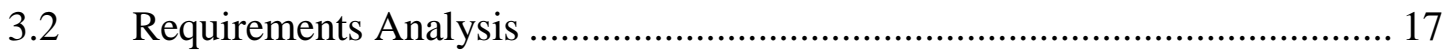

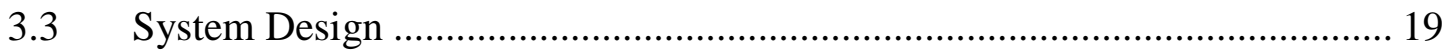

$3.4 \quad$ Project Plan ................................................................................... 20

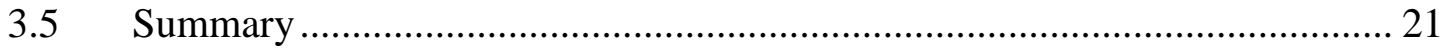

Chapter 4 - Database Design................................................................................... 23

4.1 Conceptual Data Model ....................................................................... 23 


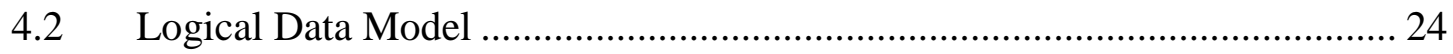

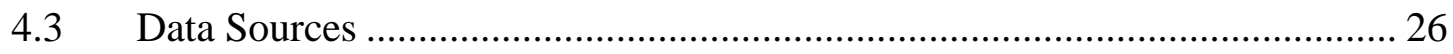

4.4 Data Collection Methods .................................................................... 28

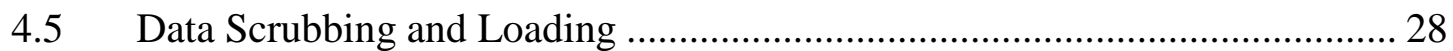

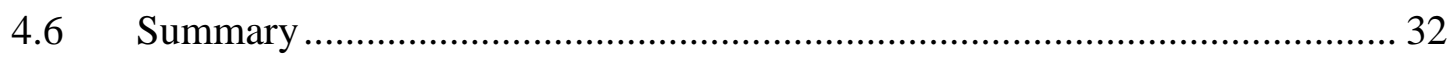

Chapter 5 - Implementation..................................................................................................... 33

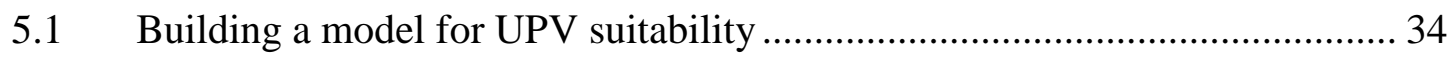

5.2 Building a model for MC3 suitability ................................................ 42

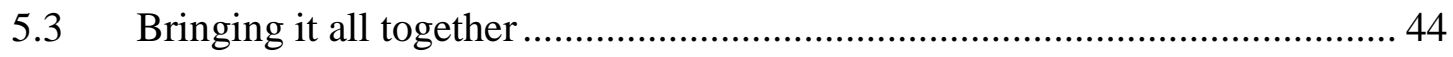

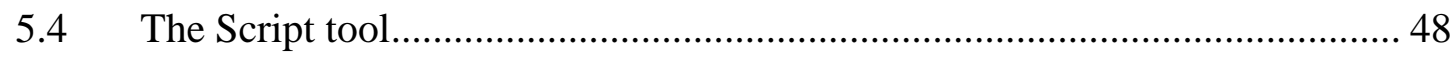

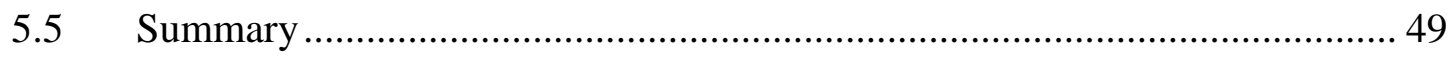

Chapter 6 - Results and Analysis......................................................................................... 51

Chapter 7 - Conclusions and Future Work ........................................................... 59

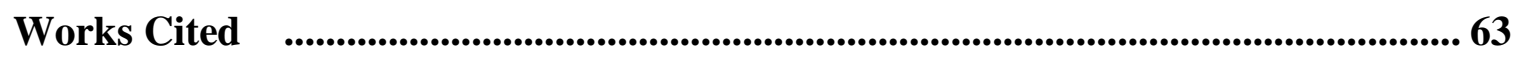




\section{Table of Figures}

Figure 1-1: DRECP area of coverage in Southern California..................................2

Figure 1-2: Rural residential areas of interest within the area of study.................... 3

Figure 1-3: The MC3 writing letters opposing a UPV proposal (Lucerne Valley

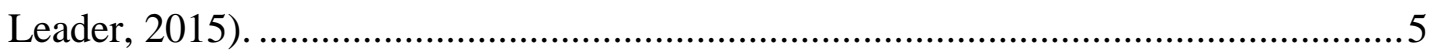

Figure 1-4: PVMapper online interface ("PV Mapper," n.d.). ................................ 7

Figure 2-1: Increase of utility-scale PV power stations over other markets (Solar

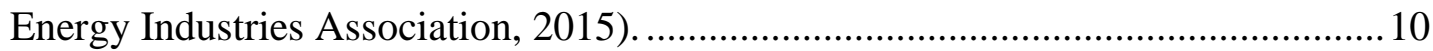

Figure 2-2: The State of California leads the nation in utility-scale solar power

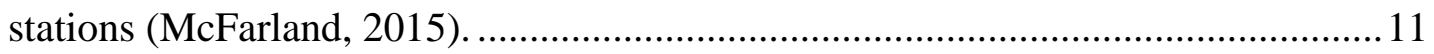

Figure 2-3: Minimal acceptable distance between a utility-scale PV and social

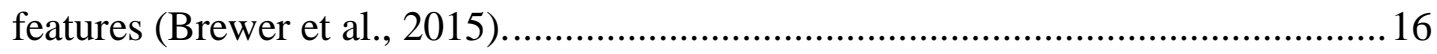

Figure 3-1: Information products were exported to a second GDB....................... 19

Figure 3-2: A Gantt chart helped visualize the scheduled timeline. ........................20

Figure 4-1: Feature layers are overlaid by their corresponding relationships. ..........24

Figure 4-2: Organization of the geodatabases and their feature layers....................26

Figure 4-3: Study Area with high desert areas of interest to the client...................29

Figure 4-4: Feature layers used in analysis for MC3 suitability.............................. 30

Figure 4-5: Feature and raster layers used in analysis for UPV suitability. ...............30

Figure 4-6: Transmission lines over housing developments.................................. 31

Figure 4-7: Green lines demonstrate where transmission lines should be located. ... 32

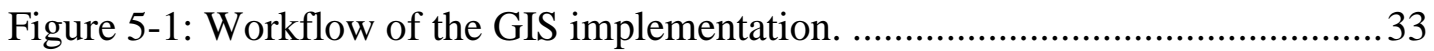

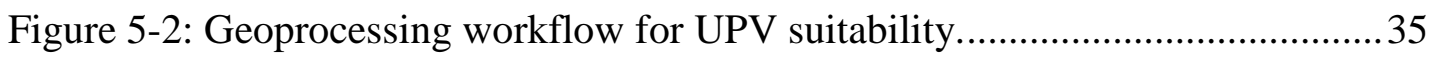


Figure 5-3: Land use data is converted into usable land cover raster.

Figure 5-4: Blank areas do not have values.

Figure 5-5: Areas in green are developed areas and unsuitable for UPV development.

Figure 5-7: Produced when solar irradiance was reclassified 1 to 9.

Figure 5-8: Graph used to determine features used in analysis (Brewer et al., 2015).

Figure 5-9: Geoprocessing workflow for MC3 suitability.................................. 43

Figure 5-10: Euclidean distance from rural residential areas.............................. 44

Figure 5-11: Areas in dark green are suitable for UPV developers. ....................... 45

Figure 5-12: Dark areas are acceptable for UPV development............................. 46

Figure 5-13: Geoprocessing workflow for the combination of UPV and MC3

suitability overlays.

Figure 5-14: Areas in blue are highly suitable for UPV development and acceptable

to the MC3.

Figure 5-15: Interface allowing the customization of the weight values.

Figure 5-16: Transmission line weight modified to a value of 9.

Figure 6-1: Produced with default weight values of 1.

Figure 6-2: Development Focus Areas (DFAs) streamline renewable energy

development.

Figure 6-3: Geoprocessing workflow to prepare the feature layer for ArcGIS online.

Figure 6-4: Areas in blue are considered suitable for UPV development. 54 
Figure 6-5: A web mapping application was used to allow comparison between SPAs and DFAs.

Figure 6-6: Close up of an existing site. Point locations allow one to click and view

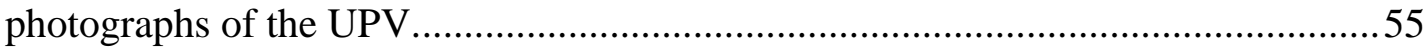

Figure 6-7: PV mapper measures social acceptance based on responses from

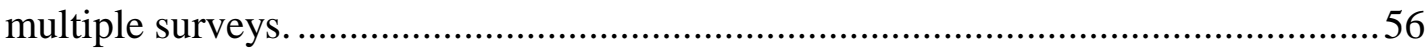

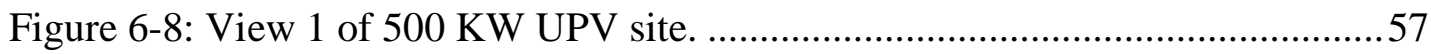

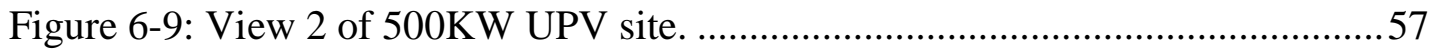

Figure 7-1: An example of possible future work............................................... 60 



\section{List of Tables}

Table 2-1: Physical parameters for UPV stations were derived at the $85^{\text {th }}$ percentile from

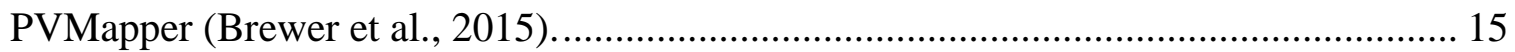

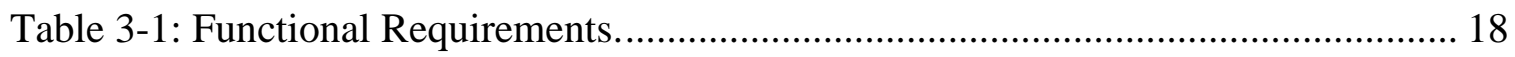

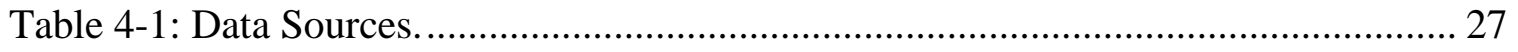

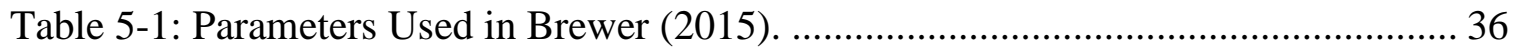

Table 5-2: Raster Values were Reclassified on a Scale from 1-9................................ 40 



\section{List of Important Acronyms and Definitions}

$\begin{array}{ll}\text { CSP } & \text { Concentrated Solar Power } \\ \text { DRECP } & \text { Desert Renewable Energy Conservation Plan } \\ \text { DFA } & \text { Development Focus Areas } \\ \text { EIR } & \text { Environmental Impact Report } \\ \text { GDB } & \text { Geodatabase } \\ \text { GIS } & \text { Geographic Information System } \\ \text { MC3 } & \text { Mojave Communities Conservation Collaborative } \\ \text { MCDA } & \text { Multiple Criteria Decision Analysis } \\ \text { NIMBY } & \text { Not In My Back Yard } \\ \text { RPS } & \text { Renewables Portfolio Standard } \\ \text { UPV } & \text { Utility Photovoltaic }\end{array}$





\section{Chapter 1 - Introduction}

The State of California has been resolute in its plan to increase energy usage from renewable sources such as wind and solar. In 2002 the State of California established the Renewables Portfolio Standard (RPS) program, which set forth the goal to increase renewable energy resources in the state to 20 percent by 2017. In 2003 the California Energy Commission wrote an Energy Action Plan that expedited the initial goal by establishing a 2010 deadline. In 2005, a redrafted Energy Action Plan recommended that the State of California require all its utility providers to obtain at least 33 percent of their energy from renewable resources by 2020. On April 12, 2011, Governor Edmund G. Brown, Jr., signed Senate Bill X1-2, which codified the recommendations of Energy Action Plan II (California Energy Commission, 2015).

In 2014, to comply with the new mandate, the California Energy Commission, the California Department of Fish and Wildlife, U.S. Bureau of Land Management, and U.S. Fish and Wildlife Service collaborated to draft an Environmental Impact Report/Environmental Impact Statement (EIR/EIS) entitled the Desert Renewable Energy Conservation Plan (DRECP). The DRECP is intended to streamline permits for renewable energy development while attempting to lessen impacts on endangered species, such as the desert tortoise, and about 22 million acres of desert landscape, shown in Figure 1-1 (California Energy Commission, 2014). 


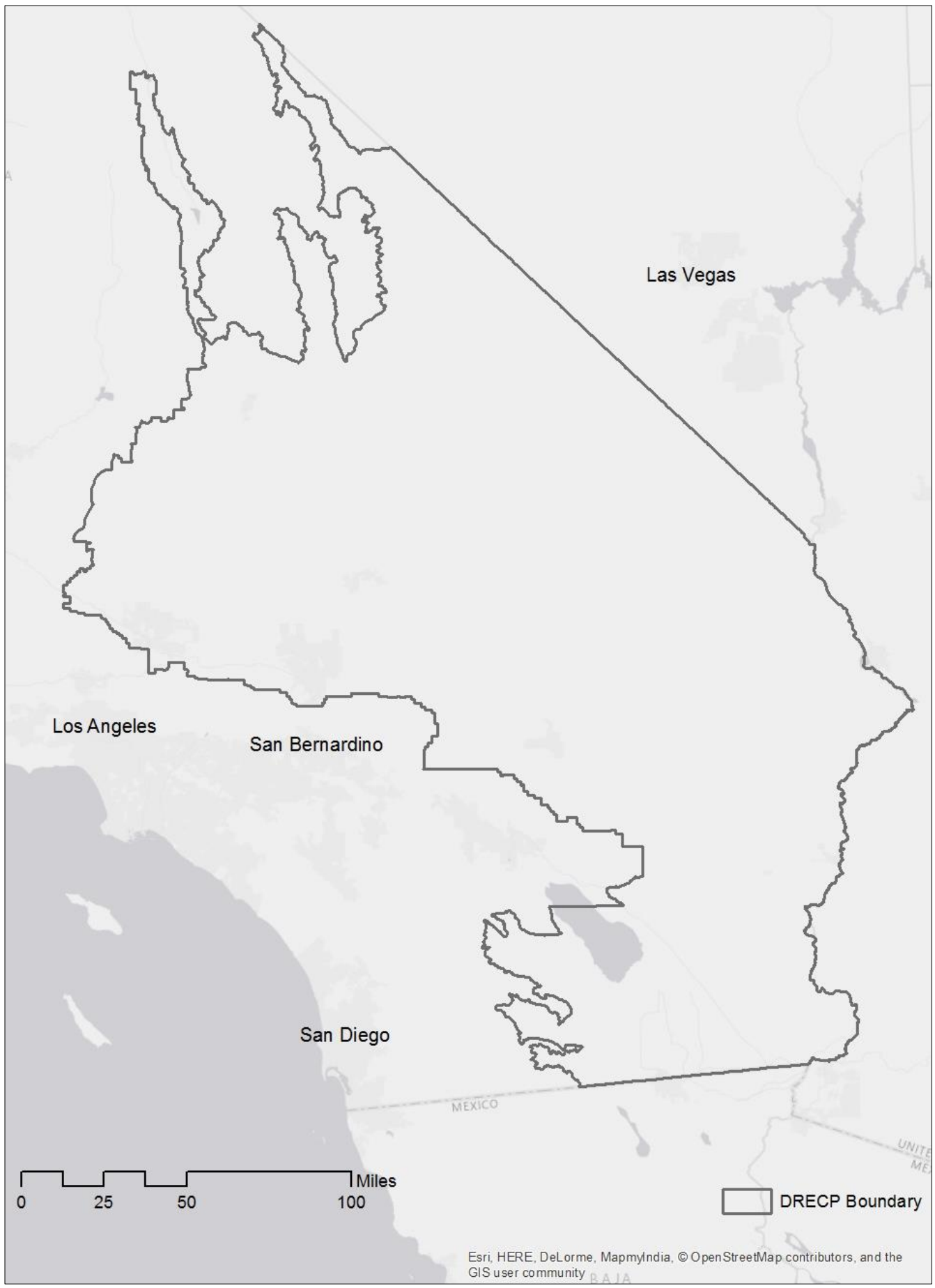

Figure 1-1: DRECP area of coverage in Southern California.

Rural residents from the high desert areas of Apple Valley, Lucerne Valley, and Phelan (Figure 1-2) opposed the drafted DRECP, because they believed the current 
format would allow development of Utility Photovoltaic (UPV) projects near their residential areas. Residents concerned about loss of the desert view-shed organized the Mojave Communities Conservation Collaborative (MC3). However, the MC3 is in a difficult position because developers and public officials may consider their opposition as a case of "Not-in-my-back-yard" (NIMBY) (Ball, 2009). A Geographic Information System (GIS) was built to help residents find a middle ground acceptable to both parties, reduce NIMBY claims, and provide visualizations that account for social preferences.

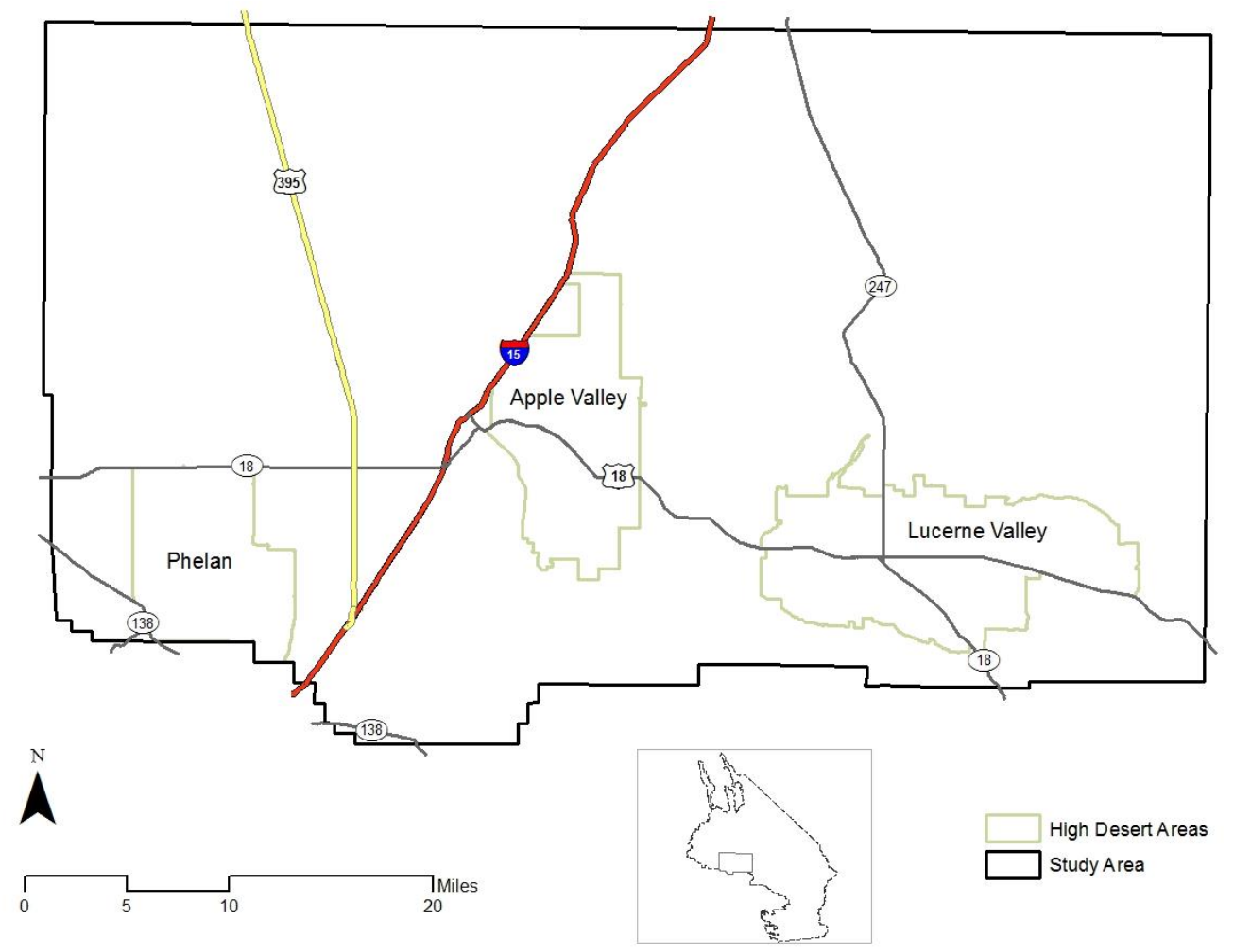

Figure 1-2: Rural residential areas of interest within the area of study.

\subsection{Client}

The client for this project was Dr. Bryan Baker, a Geospatial Software Architect for Tierra Plan, a private firm that specializes in web GIS development. Dr. Baker wanted to provide community leaders and residents with a method to visualize the potential impact 
of the UPV projects in the Mojave Desert. Specifically, he wanted to assist the MC3 in its effort against UPV projects near rural residential areas. The MC3 is primarily concerned with lowered property values as a result of UPV development's impact on desert viewshed, recreational areas, and animal habitats.

\subsection{Problem Statement}

MC3 stakeholders relied on written correspondence, such as letters and memorandums, to object to UPV proposals. However, they lacked the ability to effectively support their claims (Figure 1-3). Developers and public officials, on the other hand, often consider written objections indicative of NIMBY, which undermined the MC3 agenda. Longley, Goodchild, Maguire, \& Rhind (2011) maintained that "dynamic visualizations are far more compelling and convincing than descriptions of outcomes or statistical summaries when shown to stakeholders and the public" (pg. 406). 


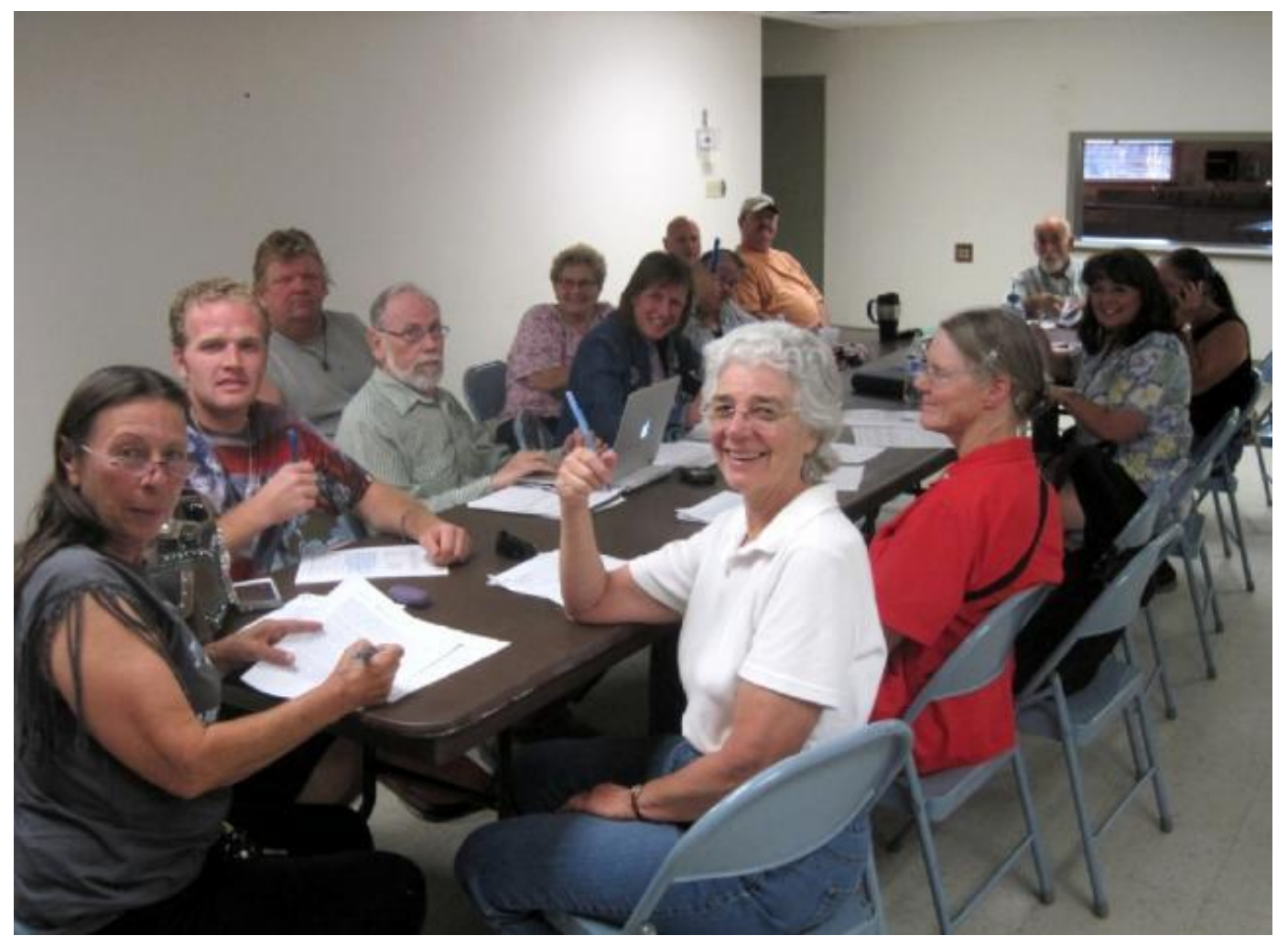

Figure 1-3: The MC3 writing letters opposing a UPV proposal (Lucerne Valley Leader, 2015).

\subsection{Proposed Solution}

A prototype tool would be developed with Esri ArcGIS software and PyScripter to allow the end user to adjust the relative importance of raster layers in a suitability analysis. Subsequently, map products would be uploaded to ArcGIS Online to compare against DRECP data by means of a web mapping application. Finally, a 3-D rendering of a UPV would visualize how a target area would look if developed.

\subsubsection{Goals and Objectives}

The goal of this project was to help Dr. Baker and the MC3 effectively mitigate UPV projects. To achieve this goal the project had three objectives:

- $\quad$ Build a prototype tool to be used with Esri's ArcGIS software 
- $\quad$ Provide a web mapping application from ArcGIS online

- $\quad$ Provide a 3-D simulation of a UPV site to enhance visualization

\subsubsection{Scope}

The project would present three information products within a ten-month period. In order to meet the specified timeline, the project was divided into three phases: initiation, implementation, and completion. Communication with the client was via email. Esri products were used for analysis because of their accessibility and the client's familiarity with them. Google Earth Pro and SketchUp were also used to enhance the final stages of the analysis.

\subsubsection{Methods}

Data for this project were collected from a number of governmental sources, including the National Renewable Energy Laboratory (NREL), U.S. Geological Survey (USGS), San Bernardino Associated Governments (SANBAG), and Desert Renewable Energy Conservation Plan (DRECP) Gateway. The latter is funded by the California Energy Commission to provide transparency during the final development of the DRECP. The software used to build the GIS for this project was Esri's ArcGIS version 10.3.1. A model for a suitability analysis of UPV stations with social preferences was built with ArcMap's Model Builder. The model was built based on parameters derived from case studies, which are discussed in Chapter 2. The suitability model was exported to PyScripter in order to allow the client to modify weights. The suitability map created by the tool was then uploaded to ArcGIS Online and compared with DRECP's Development Focus Areas (DFAs) using a web mapping application. SketchUp, ArcGIS Earth, and Google Earth were used to visualize a 3-D rendering of a UPV in its target area. Scenes of the 
rendering were incorporated into the web app to enhance visualization. The location of the 3-D model chosen was used to test for accuracy. This was accomplished by comparing the 3-D model's site score with an existing UPV suitability score. These scores were derived from PVMapper, an open source web-GIS tool that helps developers analyze suitable areas for UPV stations (Figure 1-4).

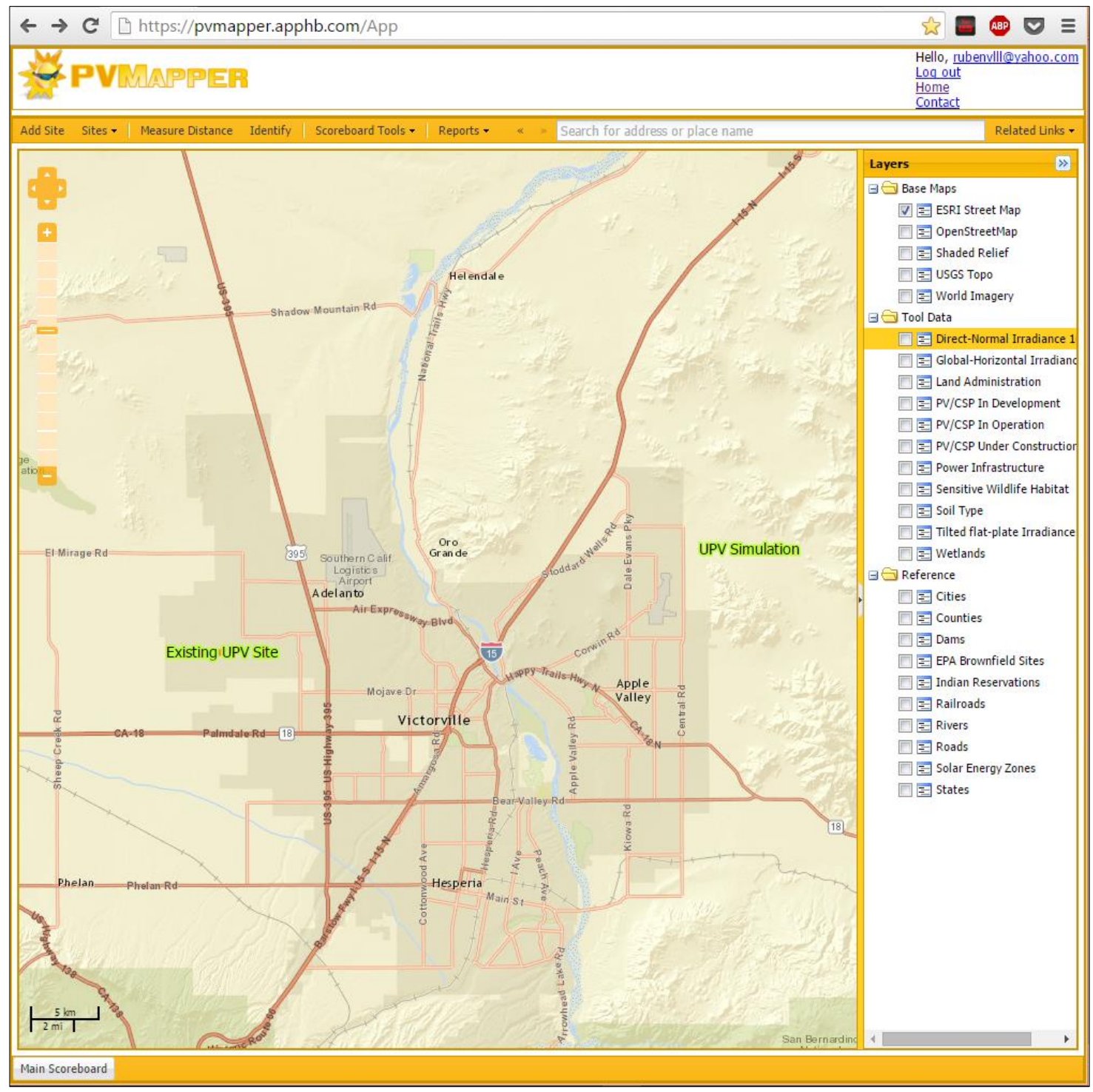

Figure 1-4: PVMapper online interface ("PV Mapper," n.d.). 


\subsection{Audience}

This report was prepared for Dr. Baker. However, the MC3 will find this report useful as it offers a general understanding of how UPV sites were chosen.

\subsection{Overview of the Rest of this Report}

An historical background of PV technology and methodologies used in prior case studies related to this project is provided in Chapter 2. The system's design and analysis are discussed in Chapter 3. The database design, as well as the conceptual data model and logical data models used for this project, are detailed in Chapter 4. In Chapter 5, the steps that were needed to solve the problem are discussed. The final results of the analysis are presented in Chapter 6. Chapter 7 provides a summary of the project and suggestions for possible areas for future work. 


\section{Chapter 2 - Background and Literature Review}

In 1839, French physicist Edmund Becquerel discovered that certain types of material absorbed light and generated small amounts of electrical current. However, it was not until 1954 that Bell Laboratories successfully developed the first photovoltaic (PV) module. A PV module works when a semiconducting wafer is treated to have a positive and negative charge to produce an electrical field. As light strikes the photovoltaic module, electrons are released from the wafer. Electrical conductors attached to the wafer then generate an electrical circuit (Knier, 2002). The space race of the 1960s further sparked research in PV technology and dramatically lowered production costs. However, it was not until the energy crisis of the 1970s that PV technology was recognized as a viable alternative energy source (Knier, 2002). By 2014, 32 percent of all new electricity generated in the United States came from solar power. Utility PV (UPV) stations account for much of the growth, with installations reaching a total energy capacity of 3.9 gigawatts (Figure 2-1). In 2014, the total energy capacity installed for all three major PV markets — residential, non-residential, and utility—-totaled 6.2 gigawatts (Solar Energy Industries Association, 2015). 


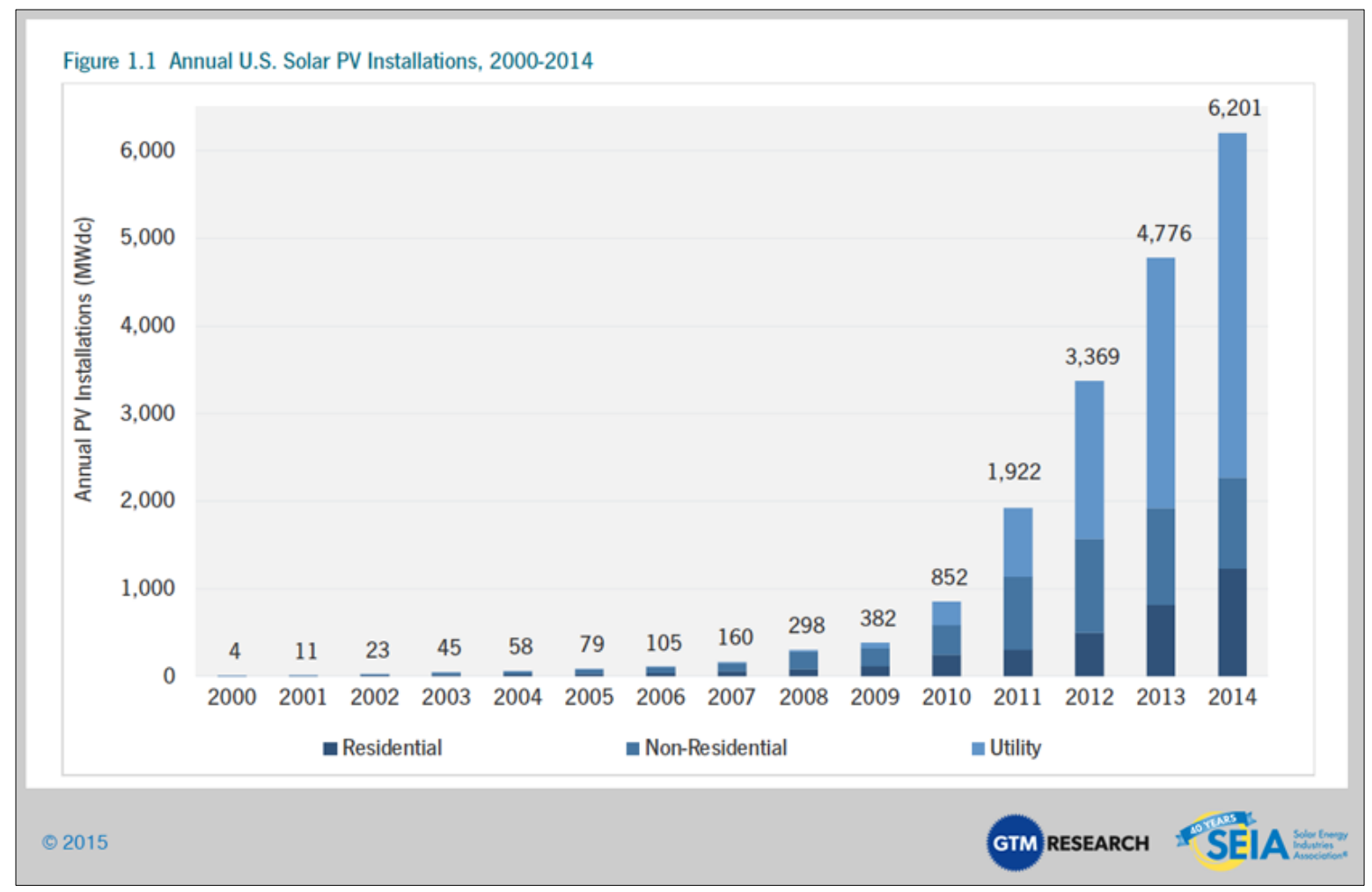

Figure 2-1: Increase of utility-scale PV power stations over other markets (Solar Energy Industries Association, 2015).

The impact of Senate Bill X1-2 is already apparent in California, where more than 5 percent of the state's energy is now being produced by UPV. In 2014 utility-scale solar projects in the state increased significantly, surpassing all other solar generating states, (Figure 2-2) (McFarland, 2015). The increase in utility-scale PV projects in California has alarmed rural residents living in areas suitable for solar energy. Residents fear that UPV projects will negatively impact their way of life (Davis, 2011; Jones, 2014; Lucerne Valley Leader, 2015; Roth, 2015). These residents are concerned about property devaluations that may result from visual blight on desert landscapes. 


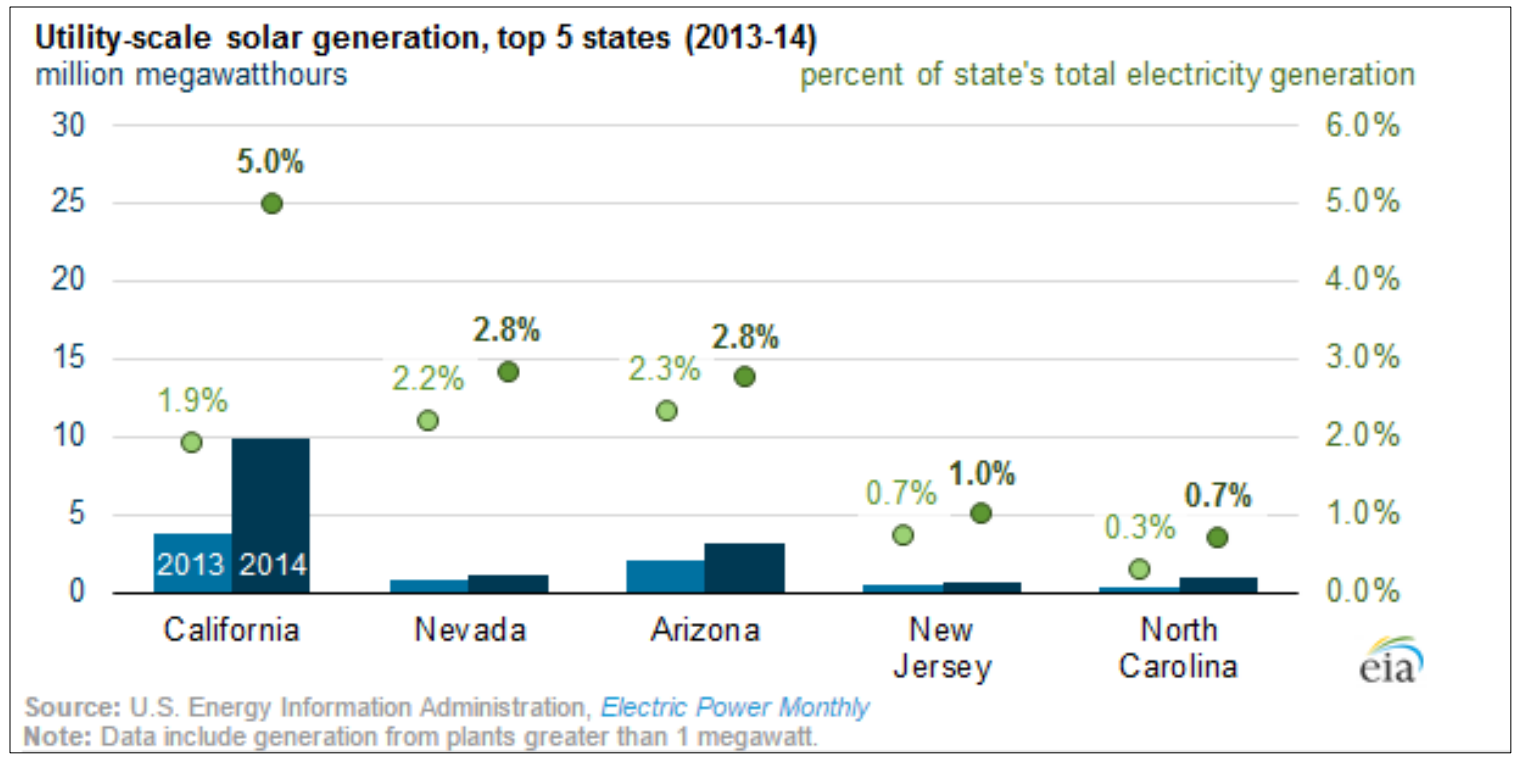

\section{Figure 2-2: The State of California leads the nation in utility-scale solar power stations (McFarland, 2015).}

NIMB Y - Not In My Backyard — is an acronym used to describe the reactions residents have when they oppose UPV projects near their communities. Worldwide, the NIMBY effect is considered to be one of the top five threats to renewable energy (Ball, 2009). NIMBY has also been described as a "syndrome that fuels the spread of misinformation" (Maiorino, 2014). Communities in different parts of the world are encountering opposition by public officials. For example, in Ontario, Canada, opposition eventually led the government to pass legislation that prohibits challenging projects for aesthetic reasons (Ball, 2009). In California, residents have encountered heavy resistance from Governor Brown, who said, "When local communities try to block the installation of photovoltaic, we act to overcome the opposition. Some kinds of opposition you have to crush" (Tyson, 2012).

This project was developed to help reduce NIMBY accusations and support residents' opposition of UPV projects near their communities. However, this project 
focused only on utility-scale PV sites and did not consider concentrated solar power (CSP) in the analysis. CSPs use a system of mirrors to concentrate solar thermal energy to drive steam engines that produce electricity (Solar Energy Industries Association, 2014). Research shows that CSPs are not likely to compete against PV technology in the foreseeable future. Therefore, a CSP project is not likely to take place within the study area.

GIS methodologies were examined from previous case studies, in order to propose a solution. Case studies revealed that a Multiple-Criteria Decision Analysis (MCDA) would be best for this project. In Section 2.1, the case studies that were used to derive the chosen methodology are discussed. Section 2.2 gives an overview of data and parameters used in prior case studies. This chapter concludes with an overall review and describes the chosen methodology.

\subsection{Suitability Methods for Utility-Scale PV Stations}

The following case studies were examined to help define the most suitable methodology for this project. Overall, case studies revealed that a MCDA is the preferred methodology for identifying suitable areas of UPV stations (Effat, 2013; McKinney, 2014; Merrouni, Mezrhab, \& Mezrhab, 2013). However, these case studies used factors that are not important to community stakeholders. For example, case studies primarily account for economic factors that help reduce costs to developers, such as proximity to transmission lines, rivers, and roads. Social factors, such as proximity to endangered habitats, and rural residential areas, were needed to satisfy this project's goal.

In a recent study, Brewer et al., (2015) incorporated the need for social preferences. He and his team developed a weighted sum model for the southwestern 
United States. The most suitable counties for solar power from each state were analyzed. Physical factors, relevant to developers, such as slope, proximity to roads, water, transmission lines, and land ownership, were overlaid to produce a Boolean map. The output was overlaid with social preferences, such as residential areas, recreational areas, and animal nesting areas, factors that were absent from most previous case studies. The project revealed that when social preferences are applied to a suitability analyses. The number of suitable areas for UPV's dramatically reduced.

In contrast, to Brewer et al., (2015). Orr (2011) did not account for social factors. This project created a suitability modeling tool for solar and wind farms in the Mojave Desert. A custom tool was built that used an ordered weighted average (OWA) technique to generate a series of raster layers from vector data, which were then categorized to help identify the most suitable locations for solar farms in the Mojave Desert. After a close inspection of three raster layers — average wind, solar isolation, and slope — the most suitable sites were selected to validate the accuracy of the model. Two existing solar farm sites were chosen to compare the final output derived from the suitability modeling tool. It was determined that these existing sites were the most suitable areas for solar farms.

A MCDA with a weighted linear combination (WLC) technique was used to identify the most suitable areas for solar farms in Colorado. Janke (2010) used the following factors: solar potential, landcover, federal lands, roads, transmission lines, and cities. Population density, was used to measure areas with low population. These factors were reclassified according to their suitability and assigned weights according to their level of importance. Output layers derived from analyses were then spatially overlaid. Map output 
visualizations helped show that the State of Colorado is minimally suited for UPV stations.

In Hott and Santini, (n.d.), a MCDA with a Boolean overlay technique was implemented to assess criteria set by threshold of suitability to create Boolean maps. This method was used to identify potential UPV sites in Wyoming. In this project, aspect, slope, solar potential, city and county boundaries, landcover, and transmission lines were used as data variables in the suitability model. First slope, aspect, and landcover were combined using map algebra. Then two analyses were conducted: an analysis of suitable locations based on populated areas, and an analysis of suitable locations based on transmission lines. These layers were overlaid and the best locations for solar farms were identified.

\subsection{Parameters for UPVs}

In order to adequately provide a solution to the problem, four factors-technical, economic, environmental and social— were analyzed (Brewer et al., 2015; Effat, 2013). Technical, economic, and environmental factors are dependent on low-level terrain, proximity to infrastructure, and suitable land use. However, social factors are complex in nature and cannot be clearly defined because they change over time. For example, during the construction of a solar project, residents may oppose noise, traffic, and dust (Brewer et al., 2015; Lucerne Valley Leader, 2015). However, these factors may subside when the construction is completed, making it difficult to determine which aspects to incorporate when considering social factors.

The primary goal of this project was to build a model that used factors important to the MC3. The literature review demonstrated, Brewer et al., (2015) was the most relevant 
case study because social factors were best accounted for in the study. This was an important finding since social factors were not of primary focus in other land suitability case studies of UPV stations. As a result, in order to construct the suitability model, for the current study, feature layers and their parameters were referenced from Brewer et al., (2015) (Table 2-1 and Figure 2-3). Social factors in the current project were accounted for by measuring "proximity" from land features important to MC3 stakeholders. Parameters were used for general guidance, but were not used in analysis. Instead, a script tool was built that allowed the end user to input weight values.

In Brewer et al., (2015), the top 100 solar farm sites in the southwestern U.S. were uploaded into an open source web-GIS tool named PVMapper which helps analyze suitable areas for UPV stations ("PV Mapper," n.d.). The parameters shown in Table 2-1 were derived from statistical analysis at the 85 th percentile to remove outliers. Out of all of the UPV stations sampled, 85 percent fell within the specified parameters (Brewer et al., 2015).

Table 2-1: Physical parameters for UPV stations were derived at the $85^{\text {th }}$ percentile from PVMapper (Brewer et al., 2015).

\begin{tabular}{|l|c|c|}
\hline \multicolumn{1}{|c|}{ Feature layer } & Parameter & Weight Value \\
\hline Road proximity distance $(\mathrm{km})$ & .56 & 1 \\
\hline River proximity distance $(\mathrm{km})$ & 17.3 & .8 \\
\hline Power line proximity distance $(\mathrm{km})$ & 32.7 & 1.1 \\
\hline Solar irradiance $-\left(\mathrm{kwh} / \mathrm{m}^{2} / \mathrm{day}\right)$ & 6.5 & 1 \\
\hline Maximum slope $($ degree $)$ & 3.1 & \\
\hline
\end{tabular}


In 2012, residents were surveyed to help identify acceptable distances between UPVs and the following social features: residential areas, agricultural lands, cultural resources, animal breeding grounds, and recreational areas. The survey generated four categories: less than a mile, 1-5 miles, 6-10 miles, and more than 10 miles. Figure 2-3 shows percentages by social feature. For example, for residential areas almost 60 percent of respondents supported UPV sites when built more than a mile away (Brewer et al., 2015).

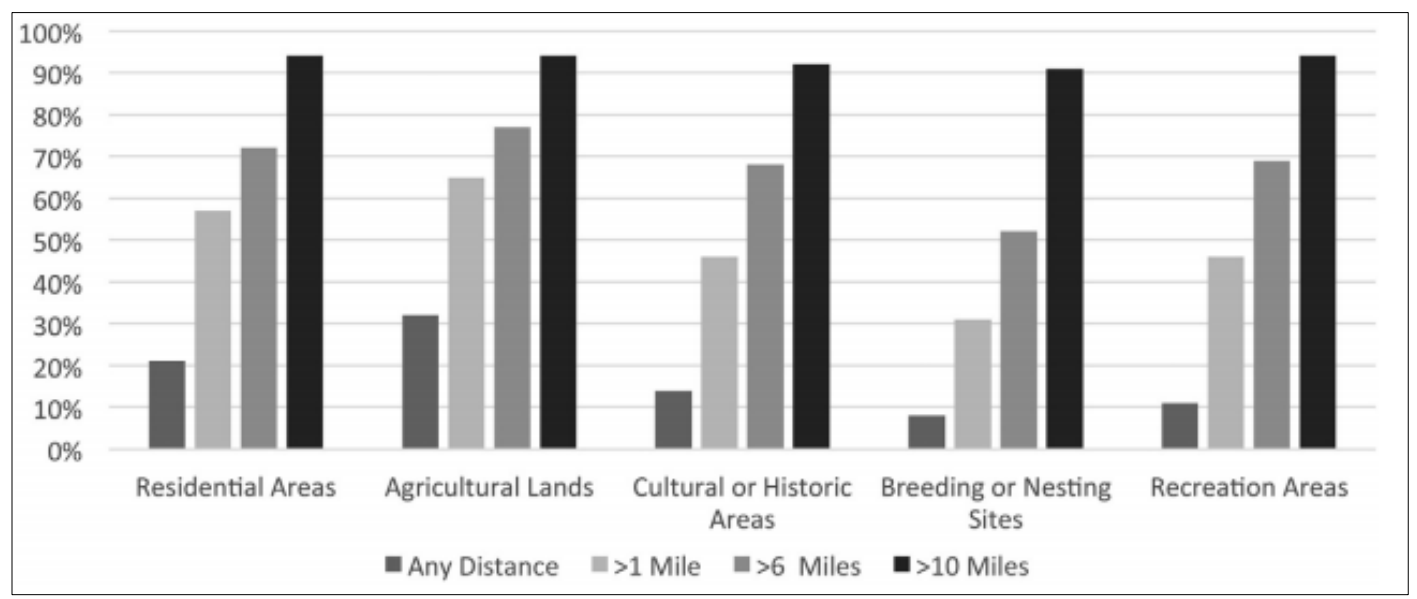

Figure 2-3: Minimal acceptable distance between a utility-scale PV and social features (Brewer et al., 2015).

\subsection{Summary}

A literature review of different case studies revealed that multiple methods exist to perform a MCDA with a GIS. According to Greene et. al., (2011), a weighted linear combination (WLC) technique using a weighted overlay or map algebra is the best method to conduct MCDA because only IDRISI and CommonGIS software provide complete integration of MCDA. Therefore, this project built a suitability model with Esri's Model Builder to perform an overlay analysis. This method can provide the client with the flexibility to control weights and explore their trade-offs in future analyses. 


\section{Chapter 3 - Systems Analysis and Design}

In this chapter the functional requirements and the system design for the GIS are discussed. This step was necessary in order to plan for the database design, which is described in Chapter 4.

\subsection{Problem Statement}

The Mojave Communities Conservation Collaborative (MC3) relies on writing letters in objection to utility photovoltaic (UPV) proposals. This course of action alone, however, may not serve their purpose since the developers and public officials may consider written proposals indicative of "not-in-my-back-yard" (NIMBY) responses. In order to support and supplement MC3 stakeholder claims with visualizations, a GIS was delivered.

\subsection{Requirements Analysis}

In order to assure the project would be successful, functional and non-functional requirements for the GIS had to be defined. A functional requirement is what a system should do, while a non-functional requirement describes how the system should perform (Eriksson, 2012). The client, Dr. Baker, will be the primary user of the GIS. As a result, non-functional requirements for the GIS were limited to the processing speeds of the client's ArcGIS software, operating system, and hardware. Google Earth and Esri Earth would be used to visualize the targeted area for the UPV model. The 3-D rendering of a UPV model was not a functional requirement of the GIS because it was built and housed independently. 
Functional requirement 1 (Table 3-1) describes the prototype tool that was created with PyScripter. The script tool is an important functionality of the GIS because it allows the end user to modify default weight values. This makes the system ready for future simulations or studies. Functional requirement 2 describes a functionality of the information products produced by the GIS. Map outputs must be comprehensible to the general public. Therefore, map legends must show suitability by classification, low suitability to high suitability, for example. Functional requirement 3 describes the web mapping application. The web mapping application must contain a slider that allows interactivity by allowing comparison between two different map layers. The application was not customized with Javascript API. This project used an application template provided on ArcGIS Online (Esri, 2015). Therefore, the application is reliant on external web browsers and servers.

\section{Table 3-1: Functional Requirements.}

\begin{tabular}{|c|l|}
\hline Functional Requirement & \multicolumn{1}{c|}{ Description } \\
\hline 1. Prototype Tool & $\begin{array}{l}\text { Must allow user-derived customization of } \\
\text { weight values }\end{array}$ \\
\hline 2. Information Products & $\begin{array}{l}\text { Must show suitable areas for UPV stations } \\
\text { by classifications within the study area }\end{array}$ \\
\hline 3. Web Mapping Application & $\begin{array}{l}\text { Must contain a slider that allows comparison } \\
\text { between adjacent map layers }\end{array}$ \\
\hline
\end{tabular}




\subsection{System Design}

A systems design (Figure 3-1) was created to minimize the risk of data deletion and to improve quality control (QC). Two file geodatabases (GDBs) were built for the GIS: GDB 1 was built to store all source data and GDB 2 was built to store all final information products. A raster schema in XML format was first imported into GDB 1 from Esri's support website to ensure a sound domain structure. Data were then collected from online sources and imported into GDB 1. A toolbox containing a script tool and model tool built with ArcMap's Model Builder was built into GDB 1. The model containing all the geoprocessing tools necessary to perform a weighted sum analysis is described in Chapter 5. The final map output produced with the prototype tool is then converted to a shapefile and uploaded to an ArcGIS Online map viewer to be used with the map application.

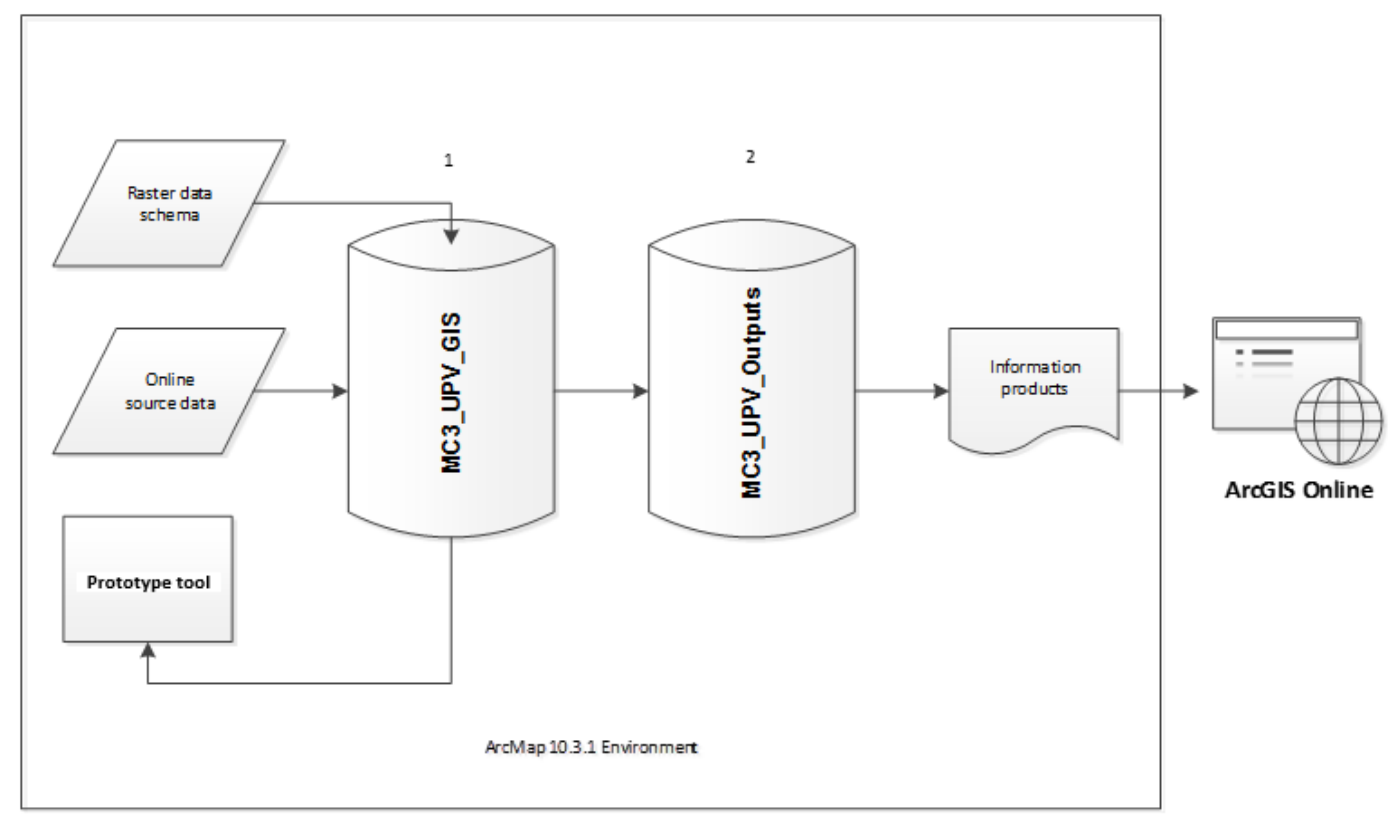

Figure 3-1: Information products were exported to a second GDB. 


\subsection{Project Plan}

At the beginning of this project the problem statement was not well defined. Therefore, there were delays during the project initiation phase. A literature review on subjects not related to this project was made in order to better understand and define the problem. This process took longer than expected. The Gantt chart (Figure 3-2) shows the project's schedule.

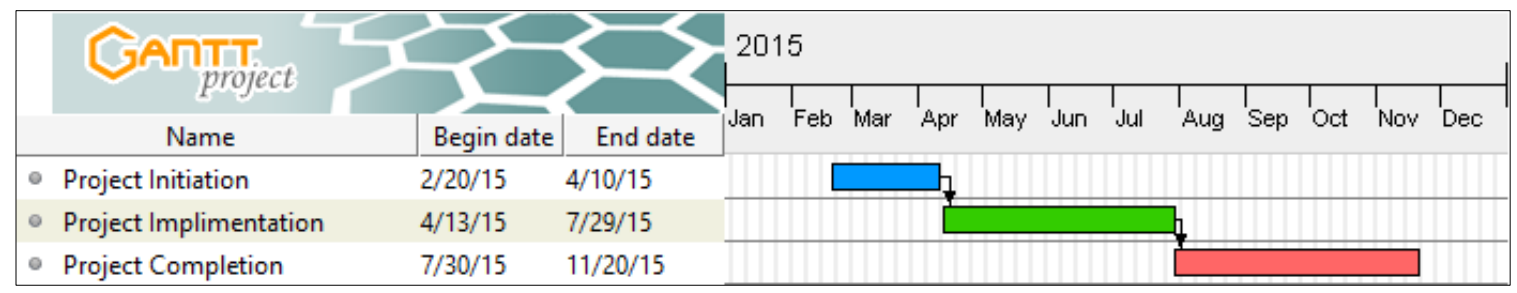

Figure 3-2: A Gantt chart helped visualize the scheduled timeline.

The project's scheduled timeline was divided into three phases: project initiation, project implementation, and project completion, and each phase was subdivided by task. Tasks within each phase needed to be completed before the project could continue to the next phase. The following list describes the major tasks needed to complete this project:

\section{- Project Initiation}

$\checkmark$ Task 1 - Research to define the goal and derive parameters for the GDB.

$\checkmark$ Task 2 - Research Esri's general methodologies and workflow.

$\checkmark$ Task 3 - Develop a conceptual model and a logical model for the GDB.

\section{- Project Implementation}

$\checkmark$ Task 1 - Build the GDB and ensure data are clean.

$\checkmark$ Task 2 - Build suitability model and prototype script tool.

$\checkmark$ Task 3 - Derive output analysis and upload to ArcGIS Online.

\section{- Project Completion}


$\checkmark$ Task 1 - Test geodatabase to ensure analysis can be reproduced by the client.

$\checkmark$ Task 2 - Review, edit, and publish web mapping application.

$\checkmark$ Task 3-Deliver completed project to the client.

\subsection{Summary}

In this chapter, functional requirements, the system's design, and the project's plan were covered. These steps were critical in order to determine whether the project was feasible in terms of time, difficulty, and relevance. Due to the lack of celerity in defining the methodology, the project's schedule was prolonged. Without a well-defined methodology, a suitability model could not be designed. In Chapter 4, the geodatabase and its data are described in detail. 


\section{Chapter 4 - Database Design}

This chapter covers the system's geodatabase (GDB) design. The GIS is composed of two file GDBs. This data management format was used because it allows containment of both raster and vector data and model building. GDB 1 (Figure 3-1) contains the source data and the toolbox. GDB 2 contains all of outputs derived from the analysis.

\subsection{Conceptual Data Model}

Brewer et al. (2015) demonstrated that relationships between technical, economic, and environmental factors are distinct from the social proximity factor because they restrict land suitability of UPV stations. A conceptual model (Figure 4-1) shows these relationships. Feature layers used for model building were grouped by their relationship in order to better arrange the model design. For example, utility suitability has a many-toone relationship, which means many feature layers relevant for UPV developers, such as transmission lines, and proximity to roads, are overlaid to produce a raster layer. MC3 Suitability is composed of feature layers from criteria relevant to MC3 stakeholders, such as rural residential areas, Mojave conservation areas, and recreational areas. These feature layers are many and are overlaid to become one raster layer. Utility and MC3 suitability raster layers were then overlaid to produce a final land suitability raster layer in a one-to-one relationship. 


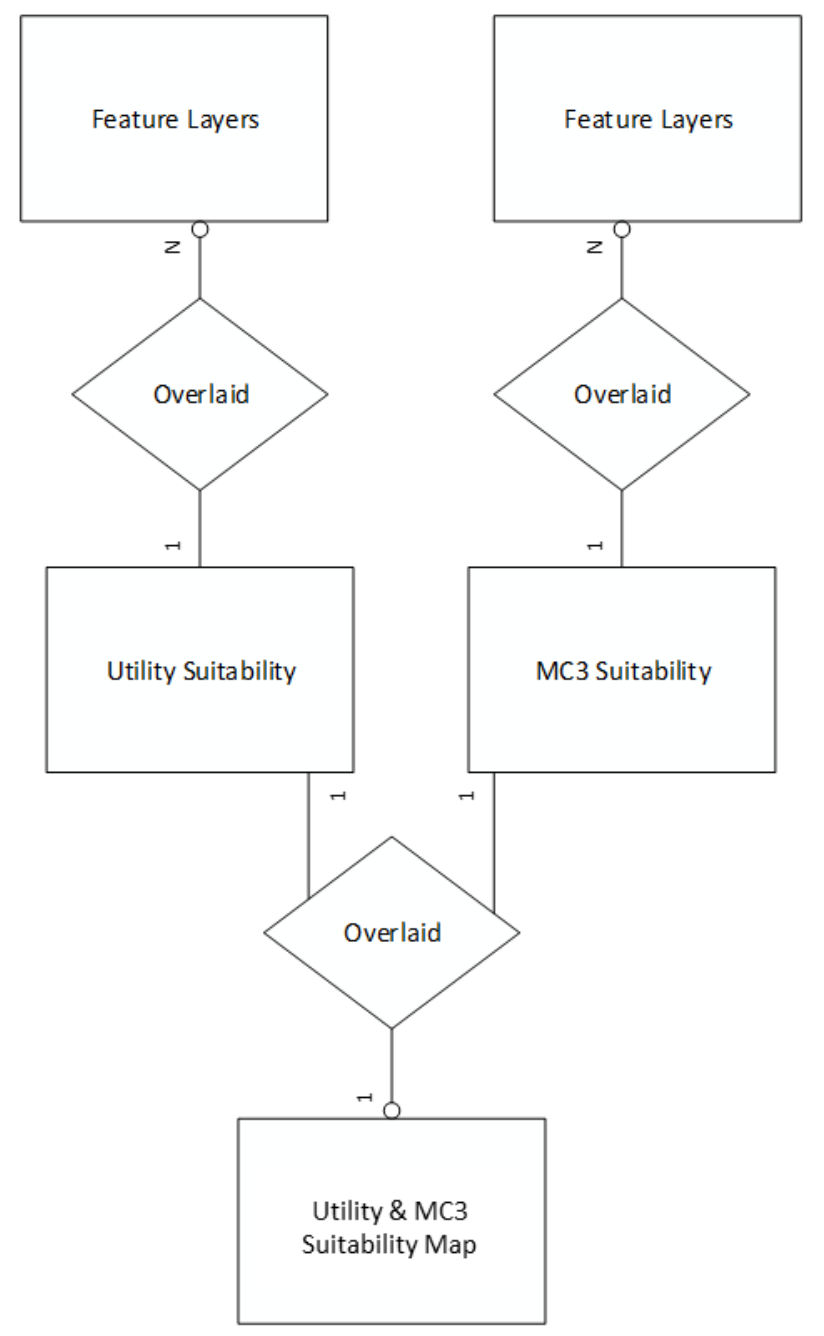

Figure 4-1: Feature layers are overlaid by their corresponding relationships.

\subsection{Logical Data Model}

Case studies served as references to determine the dataset types necessary to implement into the GDB model. As covered in Chapter 3, two file geodatabases were built in accordance with the system's design. A geodatabase file management system allows the integration of feature classes, raster datasets, and tables (Esri, n.d.). These GDBs are illustrated in Figure 4-2. Source data were used to derive new data with analysis. This was accomplished with a prototype tool stored in GDB 1. New data were exported to GDB 2 in order to safeguard against data corruption. 
Feature layers were compartmentalized and stored in accordance with the conceptual model and the following feature datasets were created:

- Comparative analysis

- Map reference

- MC3 suitability

- Outputs

- Utility suitability

The comparative analysis dataset (Figure 4-2) houses feature layers built to verify the accuracy of the outputs produced by the prototype tool. The map reference dataset is composed of feature layers needed to enhance the final map outputs. MC3 suitability, outputs, and utility suitability contain all feature layers produced by the prototype tool.

Raster datasets derived from the tool's analysis were stored independently in GDB 2. These include Euclidean distance layers, reclassified layers, and the final output layer. 


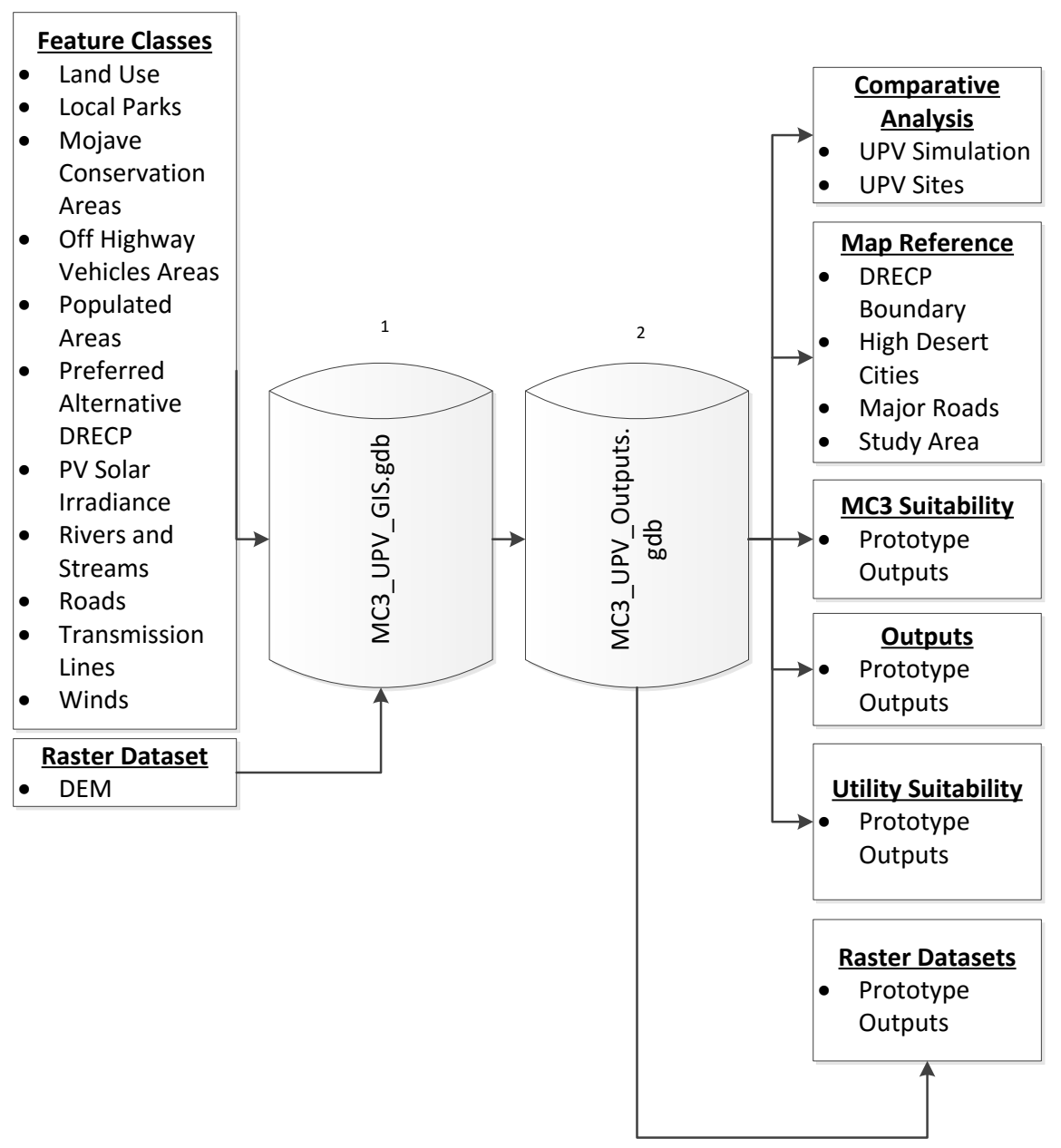

Figure 4-2: Organization of the geodatabases and their feature layers.

\subsection{Data Sources}

In order to produce a relevant GIS, the Desert Renewable Energy Conservation Plan

Gateway was used as the primary source for data (Table 4-1). The website was

recommended by the client. Data that could not be found on that site were found in governmental websites, including the National Renewable Energy Laboratory (NREL), and the San Bernardino Associated Governments (SANBAG). The Center for Spatial Studies at the University of Redlands also provided data. The client provided data for transmission power lines because it is sensitive in nature and not available to the general public. Table 4-1 shows all source data, as well as their sources. 
Table 4-1: Data Sources.

\begin{tabular}{|c|c|c|c|}
\hline $\begin{array}{c}\text { Feature } \\
\text { Layers }\end{array}$ & Description & Format & Source \\
\hline $\begin{array}{l}\text { Digital } \\
\text { Elevation } \\
\text { Model }\end{array}$ & $\begin{array}{l}\text { DRECP boundary area. Clipped } \\
\text { at } 30 \text { meter Resolution. }\end{array}$ & $\begin{array}{l}\text { Raster } \\
\text { dataset }\end{array}$ & DRECP Gateway \\
\hline Land Use & $\begin{array}{l}\text { San Bernardino County's General } \\
\text { Plan land use. }\end{array}$ & $\begin{array}{l}\text { Feature } \\
\text { Class }\end{array}$ & SANBAG \\
\hline Local Parks & $\begin{array}{l}\text { Local parks and recreational } \\
\text { areas. } \\
1: 50,000 \text { to } 1: 50,000,000\end{array}$ & $\begin{array}{l}\text { Feature } \\
\text { Class }\end{array}$ & $\begin{array}{l}\text { Center for Spatial } \\
\text { Studies }\end{array}$ \\
\hline $\begin{array}{l}\text { Mojave } \\
\text { Conservation } \\
\text { Areas }\end{array}$ & $\begin{array}{l}\text { Endangered species areas such as } \\
\text { the desert tortoise. 1: } 5,000 \text { to } \\
1: 150,000,000\end{array}$ & $\begin{array}{l}\text { Feature } \\
\text { Class }\end{array}$ & $\begin{array}{l}\text { Center for Spatial } \\
\text { Studies }\end{array}$ \\
\hline OHV Areas & $\begin{array}{l}\text { Off-Highway Vehicle } \\
\text { recreational areas. }\end{array}$ & $\begin{array}{l}\text { Feature } \\
\text { Class }\end{array}$ & $\begin{array}{l}\text { Center for Spatial } \\
\text { Studies }\end{array}$ \\
\hline $\begin{array}{l}\text { Populated } \\
\text { Areas }\end{array}$ & $\begin{array}{l}\text { U.S. census populated areas such } \\
\text { as cities. } 1: 50,000 \text { to } 1 \text { : } \\
50,000,000\end{array}$ & $\begin{array}{l}\text { Feature } \\
\text { Class }\end{array}$ & $\begin{array}{l}\text { Center for Spatial } \\
\text { Studies/ U.S. } \\
\text { Census }\end{array}$ \\
\hline $\begin{array}{l}\text { Preferred } \\
\text { Alternative } \\
\text { DRECP }\end{array}$ & $\begin{array}{l}\text { Preferred land use for the DRECP } \\
\text { draft. }\end{array}$ & $\begin{array}{l}\text { Feature } \\
\text { Class }\end{array}$ & DRECP \\
\hline $\begin{array}{l}\text { Photovoltaic } \\
\text { Solar }\end{array}$ & $\begin{array}{l}\text { Flat plate PV solar irradiance. } 10 \\
\mathrm{~km} \text { resolution grid data. }\end{array}$ & $\begin{array}{l}\text { Feature } \\
\text { Class }\end{array}$ & NREL \\
\hline $\begin{array}{l}\text { Rivers and } \\
\text { Streams }\end{array}$ & U.S. water line features. & $\begin{array}{l}\text { Feature } \\
\text { Class }\end{array}$ & $\begin{array}{l}\text { ArcGIS Online/ } \\
\text { USGS }\end{array}$ \\
\hline Roads & $\begin{array}{l}\text { Entire DRECP road network } \\
\text { includes streets and major } \\
\text { highways. }\end{array}$ & $\begin{array}{l}\text { Feature } \\
\text { Class }\end{array}$ & DRECP Gateway \\
\hline $\begin{array}{l}\text { Transmission } \\
\text { Lines }\end{array}$ & $\begin{array}{l}\text { Transmission power lines for San } \\
\text { Bernardino County. }\end{array}$ & $\begin{array}{l}\text { Feature } \\
\text { Class }\end{array}$ & Dr. Bryan Baker \\
\hline Winds & $\begin{array}{l}\text { Categorized wind strength. } \\
\text { Derived from 200-1000 meter } \\
\text { raster dataset. }\end{array}$ & $\begin{array}{l}\text { Feature } \\
\text { Class }\end{array}$ & NREL \\
\hline
\end{tabular}




\subsection{Data Collection Methods}

Only free data were used so that this project can be replicated. Data collection methods relied on online sources. Data were downloaded as compressed (zip) files and imported into the GDB, as shown in Figure 3-2. The client provided data for transmission lines. Data from the Center for Spatial Studies were imported into the GDB by accessing their network hard drive.

\subsection{Data Scrubbing and Loading}

Data scrubbing was an extensive process. Many data files came in shapefile format. Therefore, data were imported into GDB 1 in order to produce feature classes (Figure 42). The Define Projection tool was used to overwrite the coordinate system of shapefiles that did not match. Data were projected to North America Datum (NAD) 1983 Universal Transverse Mercator (UTM) Zone $11 \mathrm{~N}$, because it was the spatial reference of the source DEM. All data was measured in meters. The study area was created by incorporating boundary lines from DRECP, San Bernardino County, Edwards Air Force Base, and Lucerne Valley (Figure 4-3). 


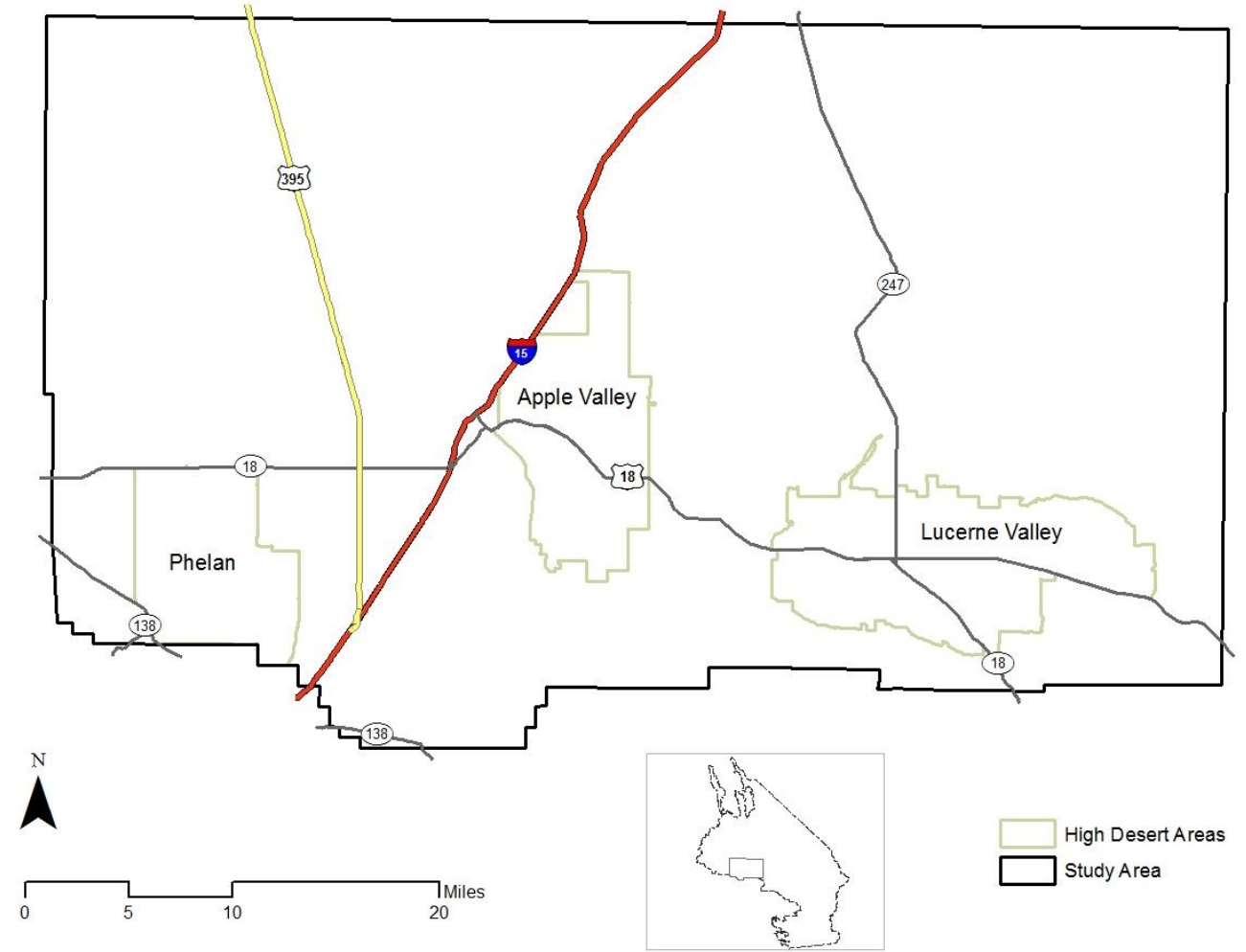

Figure 4-3: Study Area with high desert areas of interest to the client.

The study area was important to define because all data used in analyses were clipped and or masked to its boundaries. How the feature layers would look after being clipped to the study area is demonstrated in Figure 4-4 and Figure 4-5. Data were transferred to GDB 2 to avoid accidental deletion and/or corruption of data. Attribute tables were inspected for null values, incorrect features, or unnecessary fields. These were then selected and edited. This was accomplished with the execution of the model built for this project. 


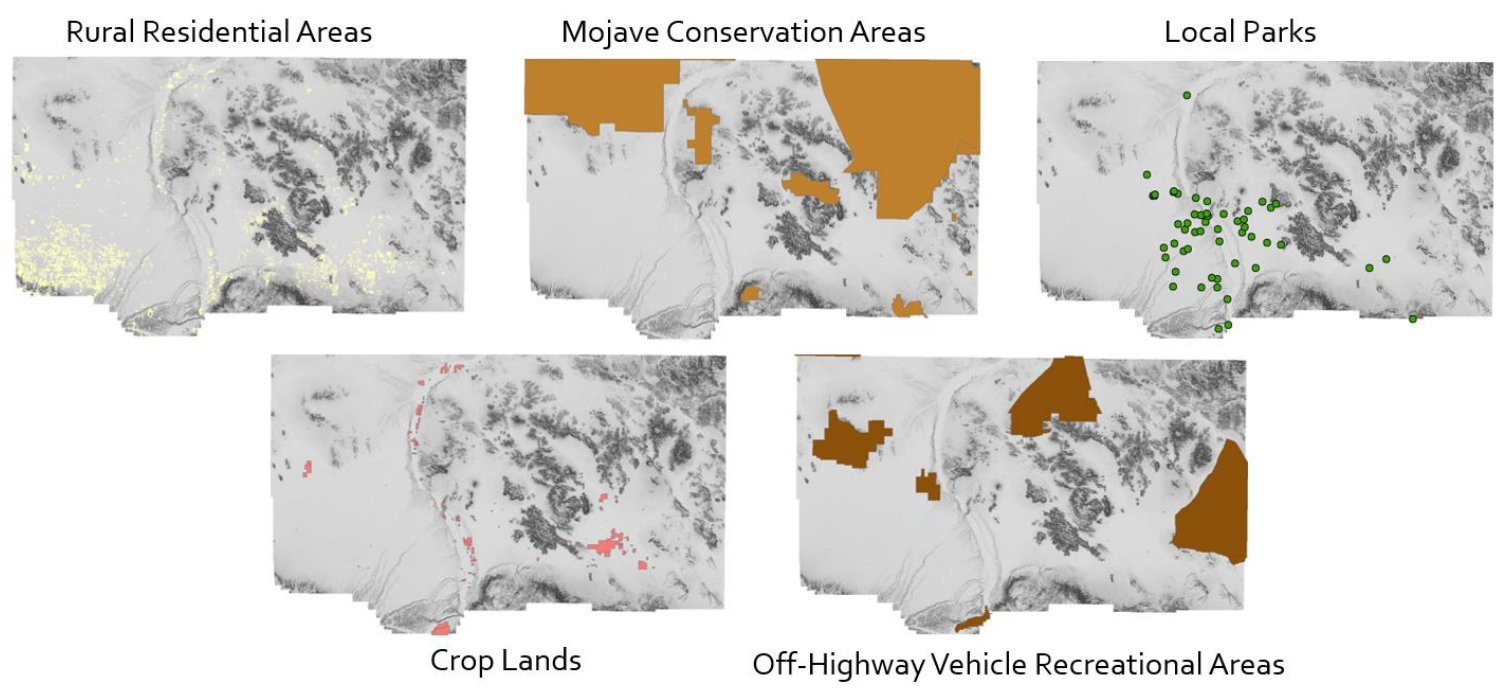

Figure 4-4: Feature layers used in analysis for MC3 suitability.
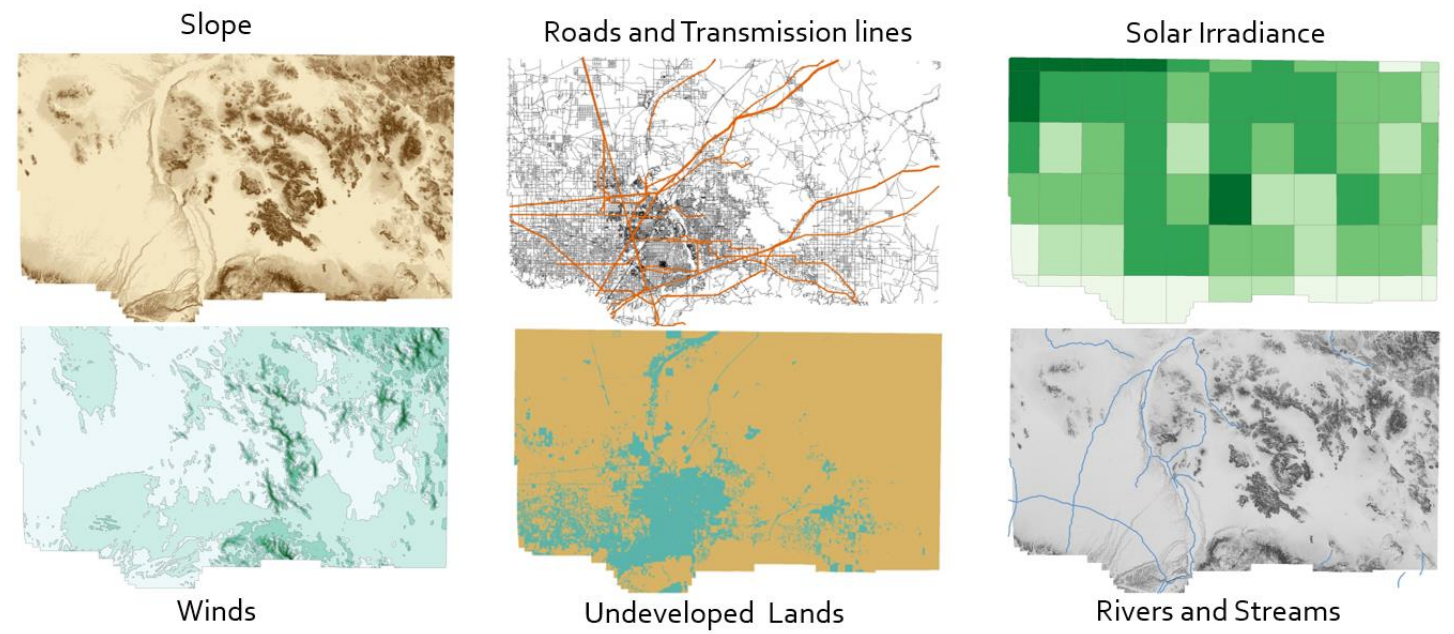

Figure 4-5: Feature and raster layers used in analysis for UPV suitability.

Data were inspected for accuracy by visually comparing them against an online image base map in ArcMap. For example, random areas within the study area were magnified in order to determine if a feature layer was aligned with the imagery. This method led to the discovery that one of the data sources used for transmission lines collected from the USGS SAGEMAP website was incorrect, see Figures 4-6 and Figures 
4-7. The client was contacted and new transmission line data were collected with assistance from his firm.

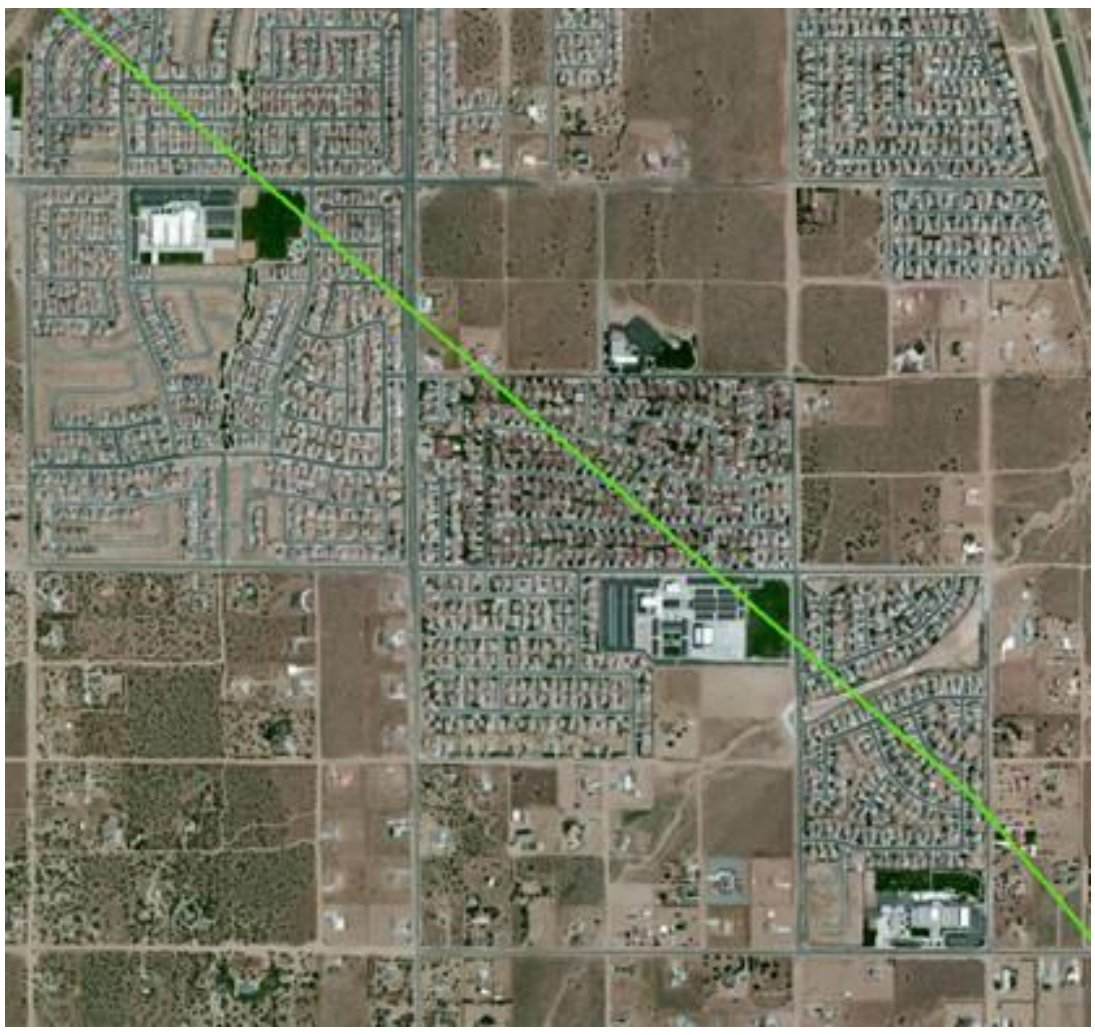

Figure 4-6: Transmission lines over housing developments. 


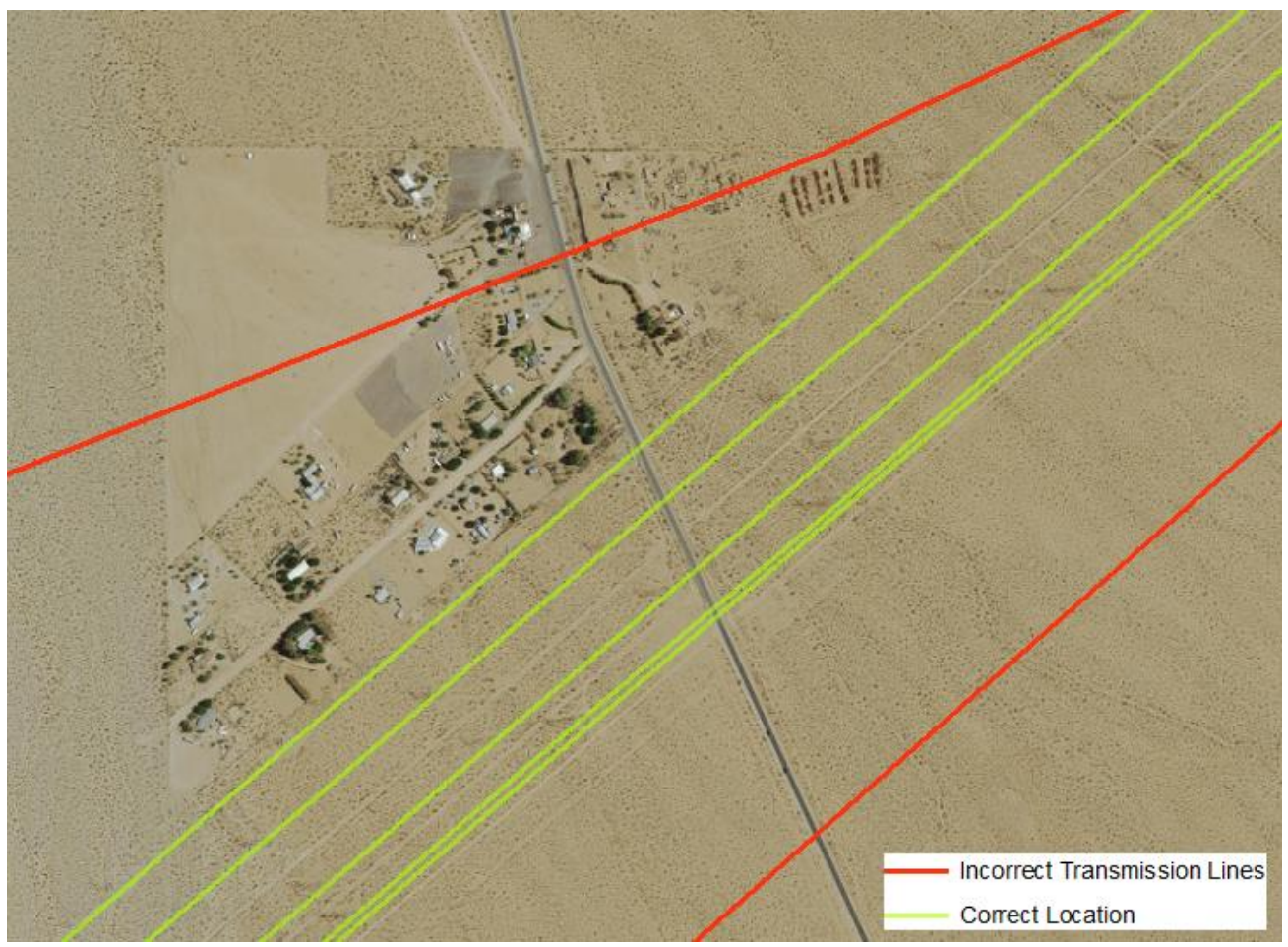

Figure 4-7: Green lines demonstrate where transmission lines should be located.

\subsection{Summary}

In this chapter, the conceptual data model (Figure 4-1) which was used to understand how the problem would be solved was discussed. This process lead to the creation of a logical data model that helped visualize the data types to leave out or import into the GDBs (Figure 4-2). Finally, a description of data sources was presented with an explanation of how the data were scrubbed to ensure accuracy. 


\section{Chapter 5 - Implementation}

In this chapter, the database design implementation is discussed. This includes a

discussion of how the prototype tool was generated. The diagram in Figure 5-1 shows the workflow of the project.

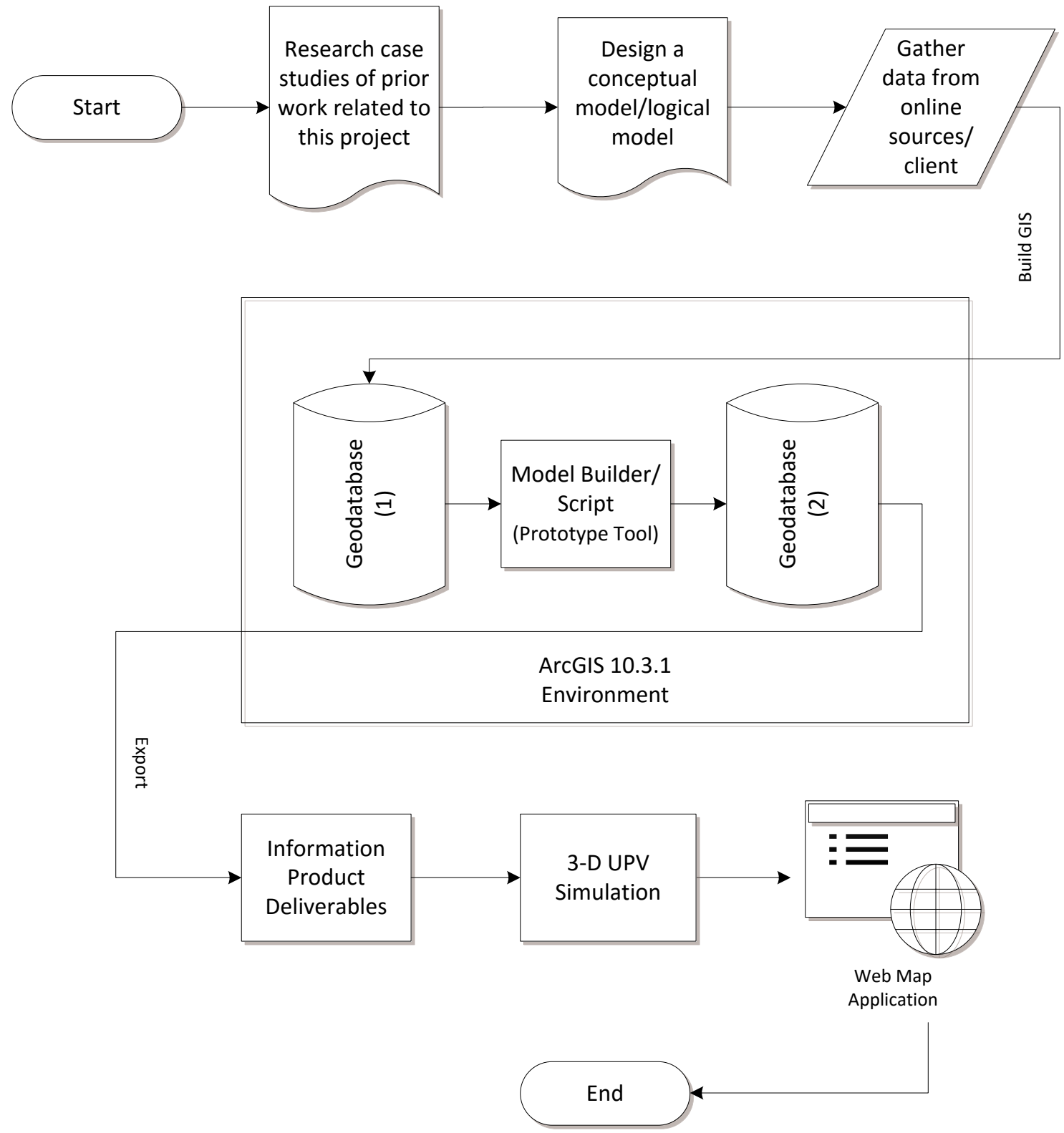

Figure 5-1: Workflow of the GIS implementation. 
This project began by researching methodologies that would provide the best solution to the problem. However, that problem had not been clearly defined. The client was interested in simulating UPV impacts on rural residents. In order to create that capability, suitable areas for UPVs had to be defined first. This approach was validated when it was later understood that the MC3 used a letter writing campaign to oppose UPV development. A GIS provided the non-profit with a visual way of justifying their opposition thereby reducing NIMBY claims. Once suitable areas were defined, impact simulations on the desert viewsheds could be explored. This project provided two scenarios to use with the GIS map outputs: a web mapping application as an effective method of rallying support; and simulation a targeted site with a 3-D UPV model. The client now has the ability to conduct further analyses with the prototype tool provided and may further improve or build new scenarios.

\subsection{Building a model for UPV suitability}

The data types were referenced from case studies explored in Chapter 2. Data preparation involved converting shapefiles into feature classes and converting their source projection into NAD 1983 UTM Zone 11N. A toolbox was then built for GDB 1 (Figure 5-1) to store the model built with Model Builder. The model was based on the geoprocessing workflow in Brewer (2015). 


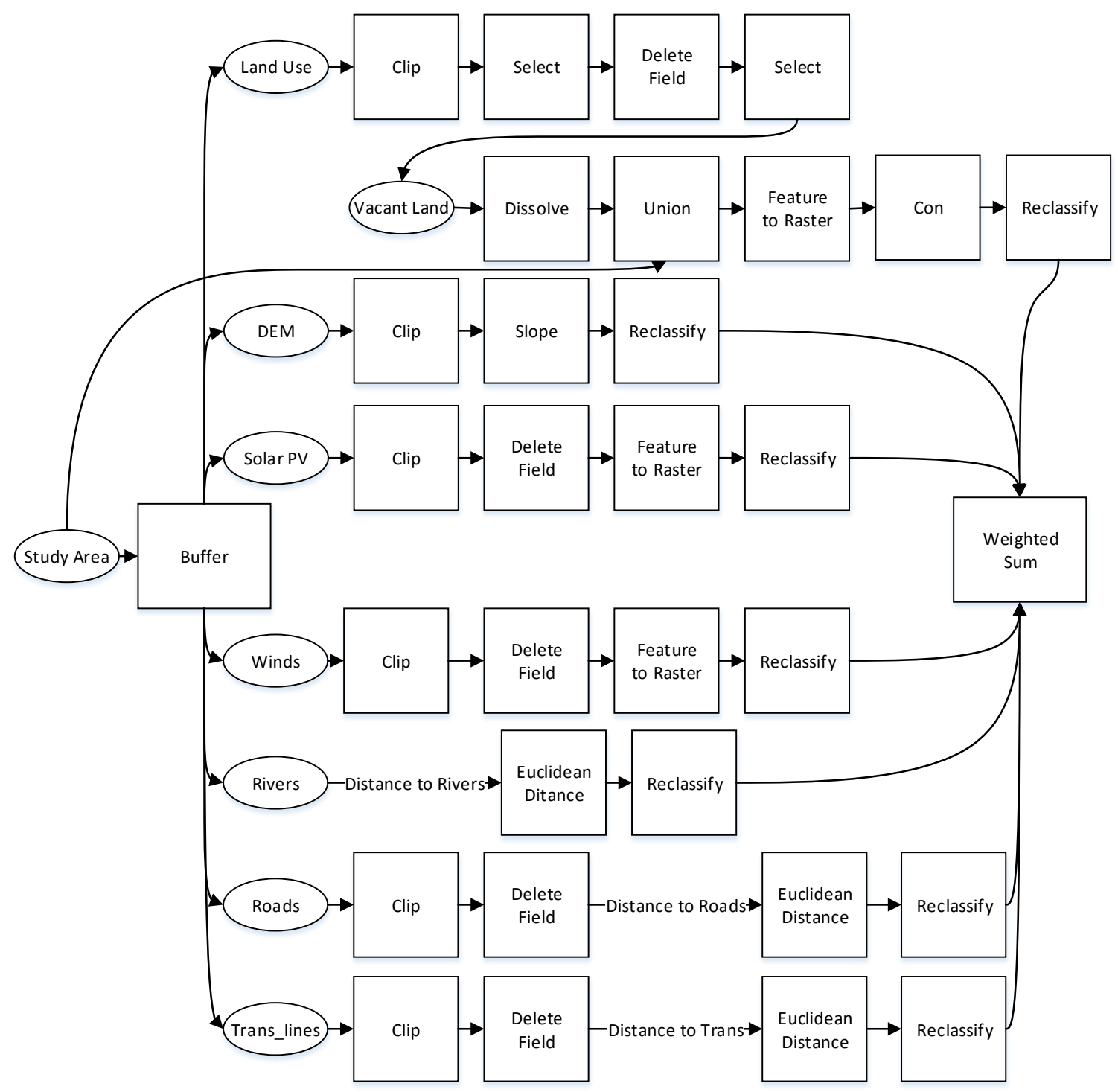

Figure 5-2: Geoprocessing workflow for UPV suitability.

The conceptual model helped organize the model in Figure 5-2. Utility suitability was composed of feature layers needed to identify suitable areas for UPV placement by means of an overlay analysis. The variables and parameters shown in Table 5-1 are 
considered preferable to a UPV developer. Solar irradiance has the highest weight because it is seen as the most important variable.

Table 5-1: Parameters Used in Brewer (2015).

\begin{tabular}{|l|c|c|}
\hline \multicolumn{1}{|c|}{ Feature Layer } & Parameter & Weighted Values \\
\hline Road proximity distance $(\mathrm{km})$ & .56 & 1.0 \\
\hline River proximity distance $(\mathrm{km})$ & 17.3 & .8 \\
\hline Power line proximity distance $(\mathrm{km})$ & 32.7 & .8 \\
\hline Solar irradiance $-\left(\mathrm{kwh} / \mathrm{m}^{2} / \mathrm{day}\right)$ & 6.5 & 1.1 \\
\hline Maximum slope $($ degree $)$ & 3.1 & 1.0 \\
\hline
\end{tabular}

In this project winds and undeveloped lands were added in addition to the variables shown in Table 5-1. Low winds are important for UPV placement because high winds can damage equipment and may lead to ground erosion (McHale, 2012). Undeveloped lands is a feature layer derived from San Bernardino County’s land use. This feature layer replaced land cover because the data collected had been corrupted and 
could not be used. Figure 5-3 illustrates the workflow used to derive the undeveloped lands output.

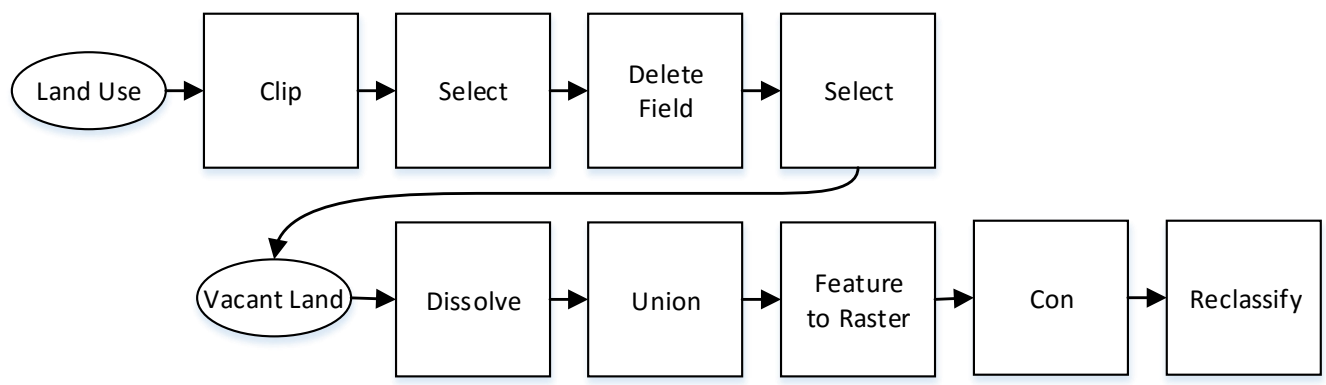

Figure 5-3: Land use data is converted into usable land cover raster.

First, the land use feature layer was scrubbed and vacant lands were extracted by means of a SQL expression:

DESC_12Fix $=$ 'Vacant Area' OR DESC_12Fix = 'Vacant Undifferentiated' OR DESC_12Fix = 'Vacant $w /$ limited Improve.'

The result is shown in Figure 5-4. Subsequently, the geoprocessing union tool was used to combine the undeveloped lands layer with the study area in order to fill no data areas (blank areas) with a -1 value. 


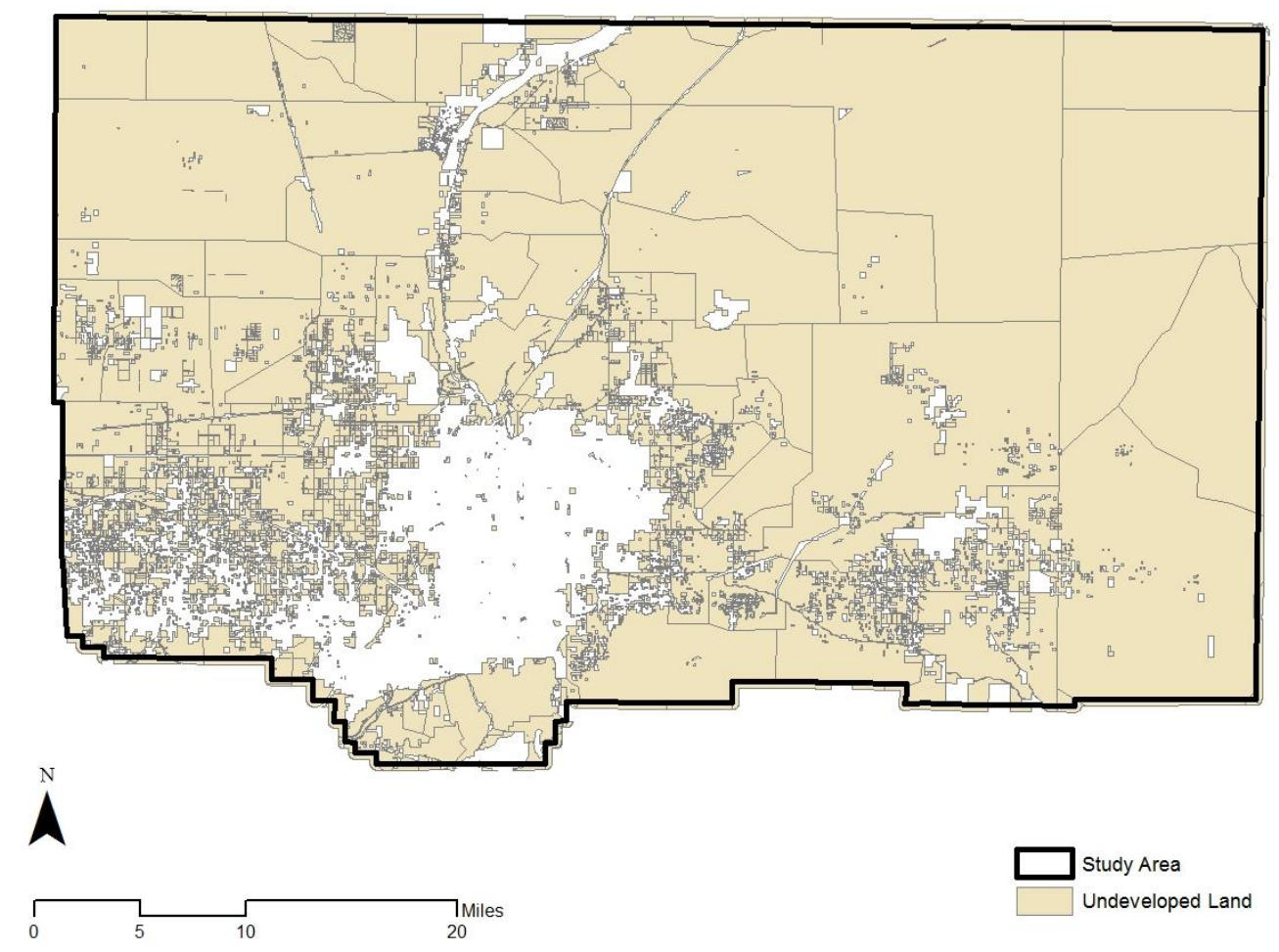

\section{Figure 5-4: Blank areas do not have values.}

After the feature layer was combined with the study area using the Union tool, the layer was converted into a raster image. The Con tool was used to replace all its -1 values with a 0 to produce a Boolean image. Areas classified as 0 were named "developed areas" and areas with a value of 1 were named "undeveloped lands" (Figure 5-5). 


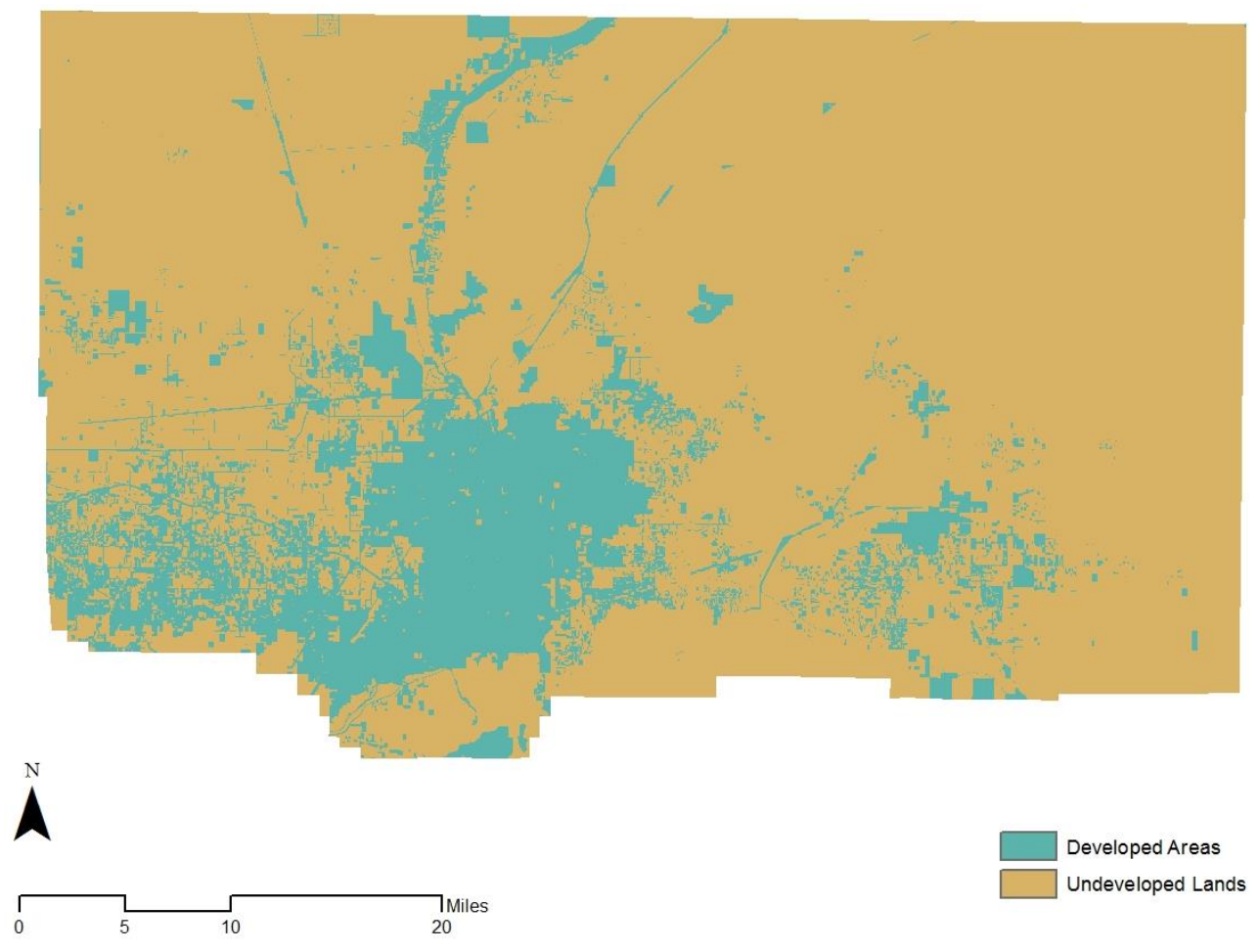

Figure 5-5: Areas in green are developed areas and unsuitable for UPV development.

The geoprocessing workflow for "UPV suitability" uses equal interval as the default classification method. However, it is intended to be modified for future simulations. This was done because the customization of specific parameters related to UPV suitability requires expert advice. As a result, weight parameters were left at 1.0.

Table 5-2 shows the parameters that were used in order to produce an output layer. Raster values were reclassified on a scale of 1 through 9 to simplify old values and enhance map symbology. 
Table 5-2: Raster Values were Reclassified on a Scale from 1-9.

\begin{tabular}{|l|c|c|}
\hline \multicolumn{1}{|c|}{ Raster Datasets } & Reclassification Values (1-9) & $\begin{array}{c}\text { Weighted } \\
\text { Values }\end{array}$ \\
\hline Roads (km) & (Distance to) 9 - 1 (Distance From) & 1.0 \\
\hline River and streams (km) & (Distance to) 9 - 1 (Distance From) & 1.0 \\
\hline Transmission lines (km) & (Distance to) 9 - 1 (Distance From) & 1.0 \\
\hline $\begin{array}{l}\text { Solar irradiance } \\
\text { (kwh/m²/day) }\end{array}$ & 9 (High irradiance) & 1.0 \\
\hline $\begin{array}{l}\text { Slope (Degrees) } \\
\text { Winds (Class) }\end{array}$ & (Low slope) 9 - 1 (High slope) & 1.0 \\
\hline Land Cover (Value) & (Developed Areas) 1- 9 (Undeveloped lands) & 1.0 \\
\hline
\end{tabular}

Roads, rivers, and transmission lines must be at close proximity to consider a site suitable for UPVs. The parameters given by Brewer (2015) define distances and weights for these variables. In accordance, Table $5-2$ shows distances reclassified from lowest to highest with values of 9 (high importance) to 1 (low importance).

Solar irradiance, the measurement of solar energy measured by kilowatt hour per square meter per day, is best for UPV sites at $6.5 \mathrm{kwh} / \mathrm{m}^{2} /$ day or greater. Solar irradiance for the entire study area exceeded this value. As a result, the solar irradiance layer was reclassified with a value of 9 (Figure 5-7). 


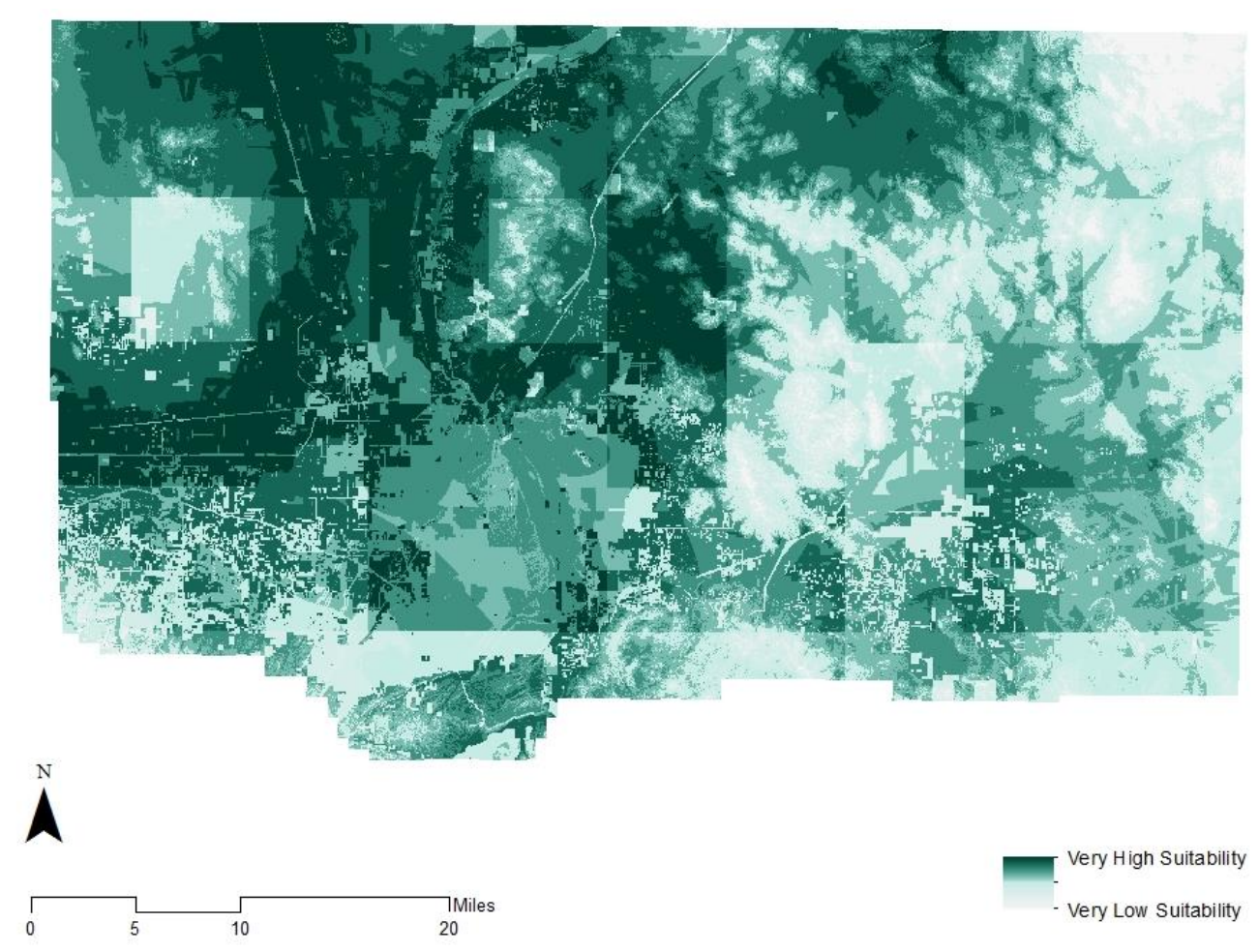

\section{Figure 5-7: Produced when solar irradiance was reclassified 1 to 9.}

Slope is of great importance in UPV placement because a level terrain lowers development costs. An area with a slope of less than 3.1 degrees is suitable. As a result, slope ranges were reclassified from 9 for low slope to 1 for high slope. Low wind is desirable for UPV placement because it lowers maintenance costs associated with soil erosion. The wind layer only contains wind speed measurements in meters per second. The National Renewable Energy Laboratory (NREL) classified wind speeds of greater than $9.4 \mathrm{~m} / \mathrm{s}$ the uppermost wind power class (WPC) of 7. As a result, WPCs of 7 were reclassified with a value of 1 (low suitability) to 9 (high suitability) for WPCs of 1 . These values were reclassified on a 1 to 9 range using the equal interval classification method. Finally, the Boolean raster layer for land cover was reclassified with 1 and 9, in order to give low importance to developed areas and high importance to undeveloped lands. 


\subsection{Building a model for MC3 suitability}

The Mojave Communities Conservation Collaborative (MC3) wants to keep the desert as it is and are also worried that property values will drop as a result of UPV developments. MC3 stakeholders do not want UPVs near endangered habitats, residential areas, or recreational areas. Therefore, data were collected to reflect MC3 criteria. Figure 5-8 was referenced from Brewer et al (2015). However, the methodology for this part of the analysis was not followed because percentages were derived from resident surveys. In addition, percentages shown in Figure 5-8 are not representative of the MC3. Therefore, distance was analyzed to determine social acceptability.

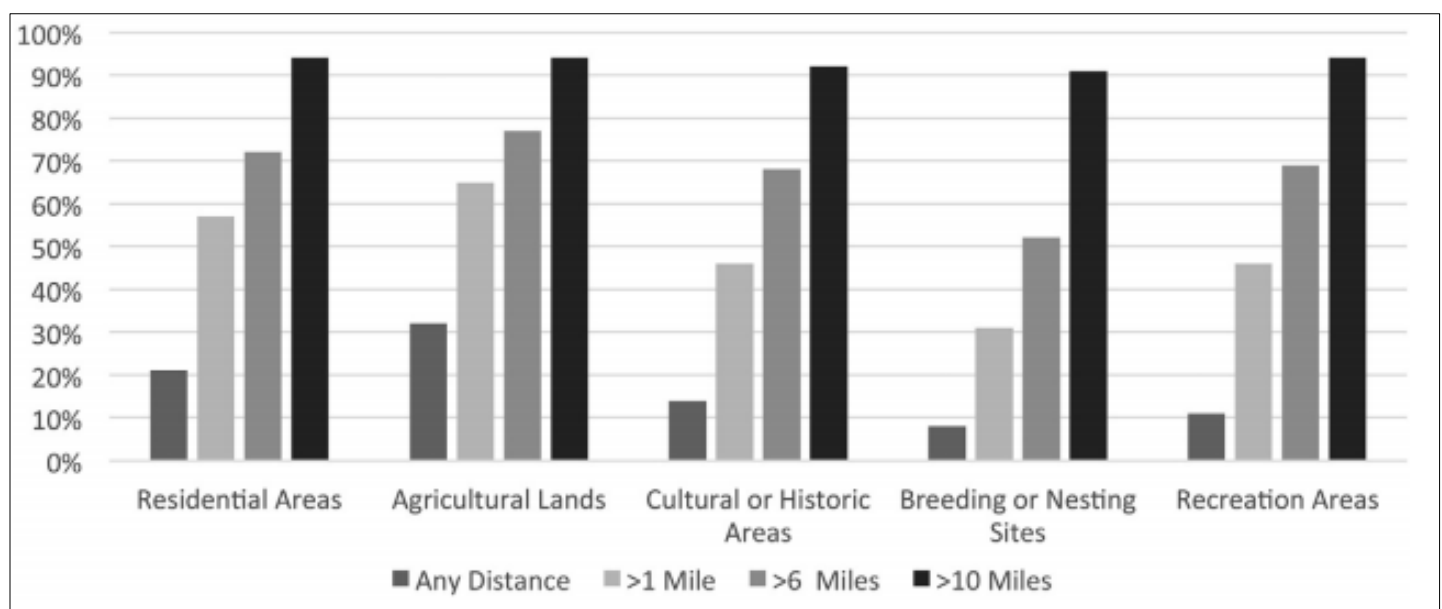

Figure 5-8: Graph used to determine features used in analysis (Brewer et al., 2015).

Mojave conservation areas, Off-Highway-Vehicle (OHV) areas, local parks, crop lands, and rural residential areas, were extracted and scrubbed. Figure 5-9 illustrates the geoprocessing workflow used for this part of the model's analysis. 


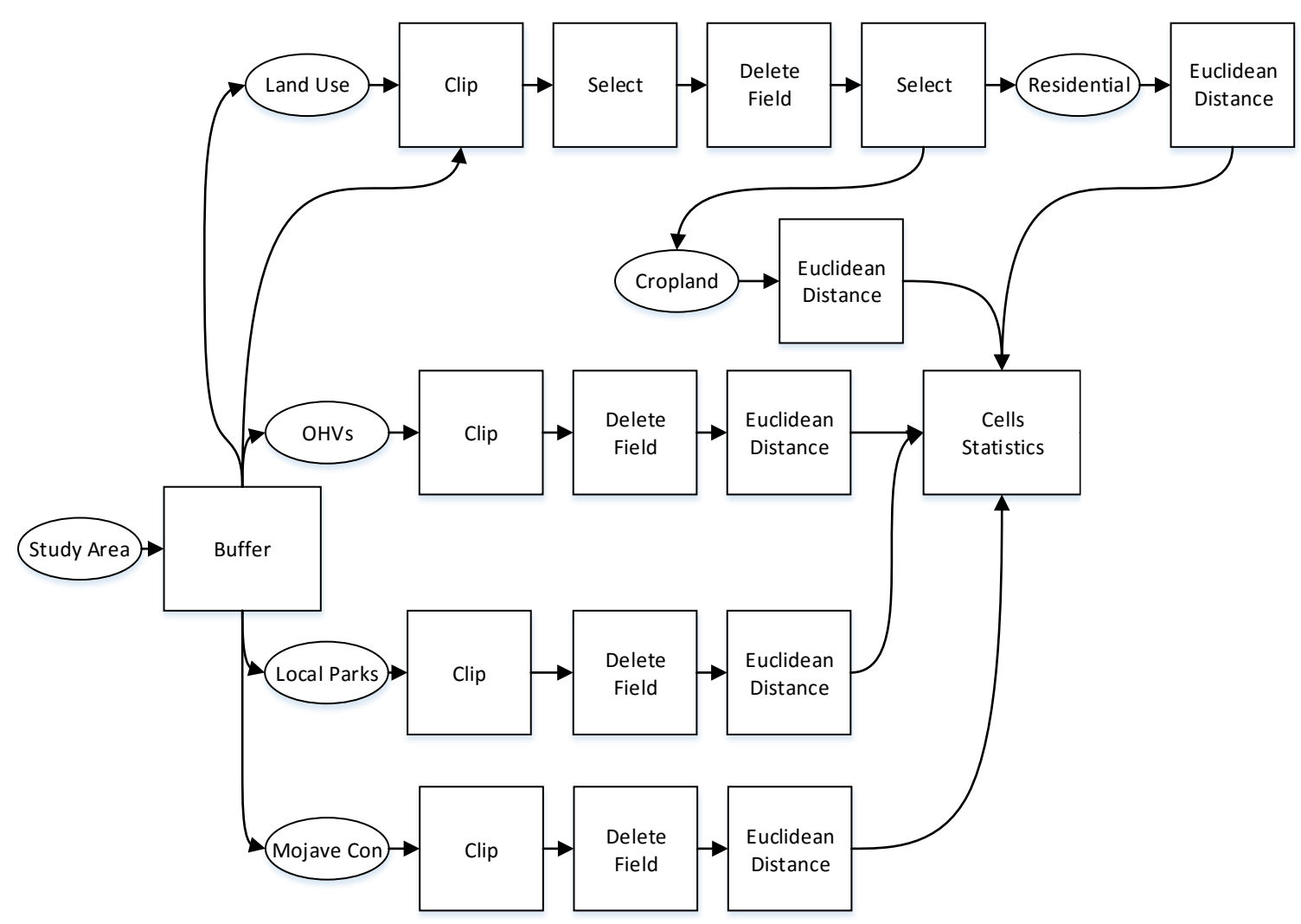

Figure 5-9: Geoprocessing workflow for MC3 suitability.

Every feature layer was scrubbed and then clipped to the study area. Then, the Euclidean distance tool was used. This tool measures the straight line distance in meters from cell center to cell center (Esri, 2012). An example of an output can be seen in Figure 5-10. Distances away from social features were analyzed as a way to satisfy the MC3; the further the distance from a given feature, the more suitable the area becomes for UPV development. The Euclidean distance tool was an effective method of converting feature classes into raster datasets. San Bernardino County land use data were used to extract two feature classes: high and low rural residential, and crop lands. Crop lands are agricultural areas. 


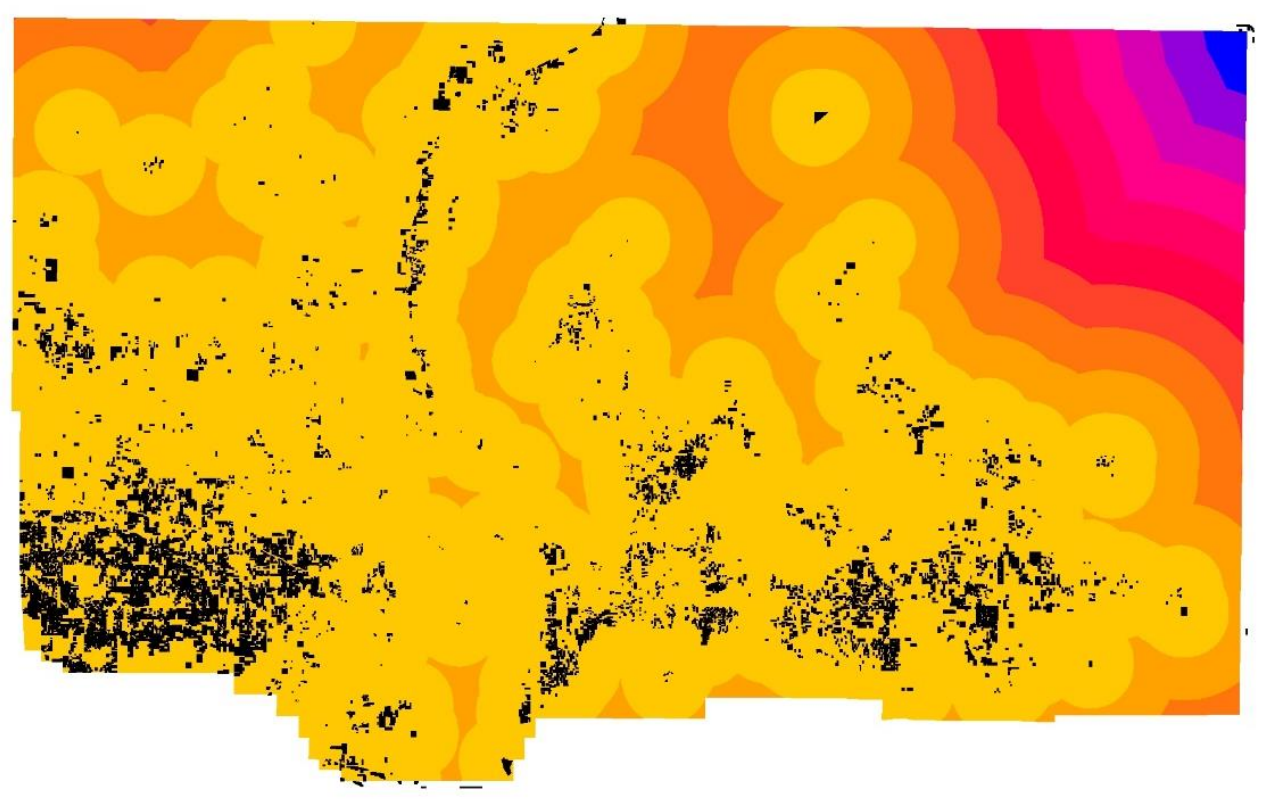

Figure 5-10: Euclidean distance from rural residential areas.

\subsection{Bringing it all together}

MC3 stakeholders wanted to preserve their way of life. However, they needed to be practical about the problem. NIMBY claims will be reduced if a middle ground can be reached with UPV developers. Therefore, map outputs from the geoprocessing workflows shown in Figures 5-2 and 5-9 had to be combined.

The weighted sum tool was used to derive the UPV suitability map in Figure 5-11. This tool works by overlaying multiple raster datasets and multiplying each by its given weight value, weights values of 1.0 (Table 5-2) were used for the prototype tool. The tools output was reclassified with values ranging from 1-9. A value of 9 indicates very high suitability. The UPV suitability map (Figure 5-11) shows the dark green areas to be considered highly suitable for UPV development. 


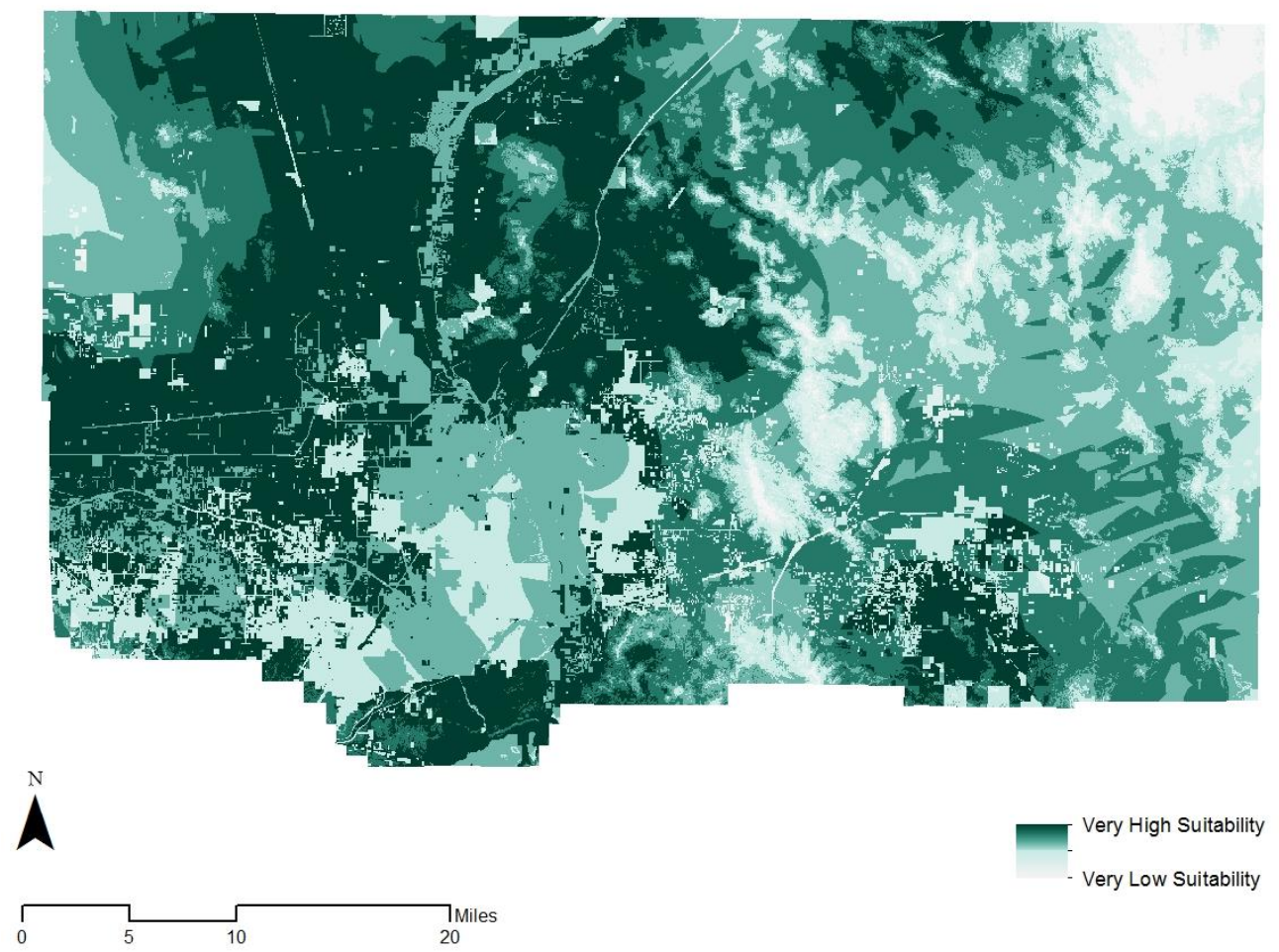

Figure 5-11: Areas in dark green are suitable for UPV developers.

The MC3 suitability map in Figure 5-12 was produced using the Cells Statistics tool as shown in Figure 5-9. The tool works by overlaying multiple raster layers (Euclidean distance outputs) and calculates statistics on a per-cell basis to produce a single output. The MC3 suitability map (Figure 5-12) shows dark areas as acceptable for UPV projects. 


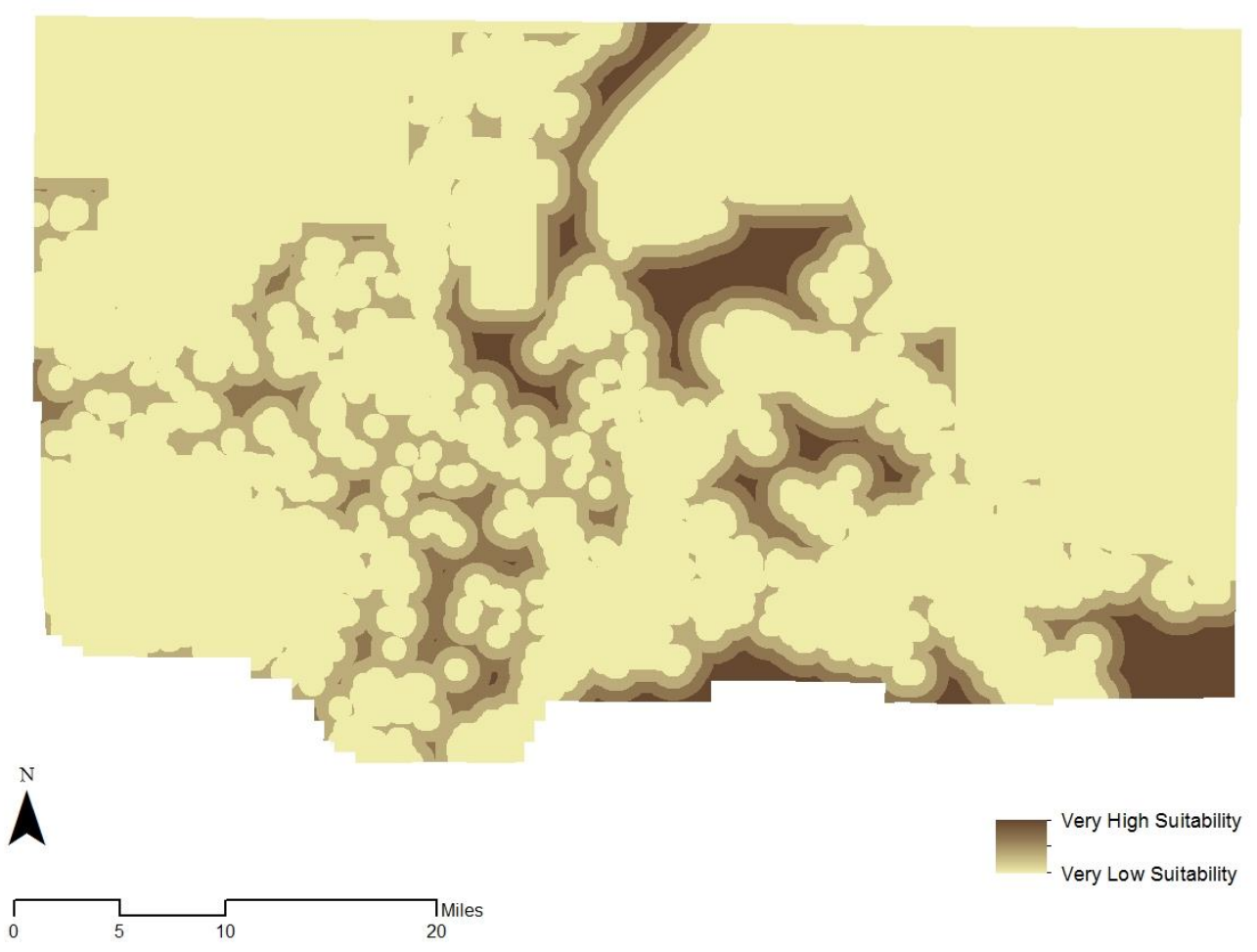

Figure 5-12: Dark areas are acceptable for UPV development.

The diagram in Figure 5-13 shows the geoprocessing workflow used to combine MC3 and UPV outputs. The Rescale by Function tool was used to rescale the minimum and maximum values for each output. In the tool's interface, the linear transformation function was selected to rescale to a range from 0 to 100 . This was done to ensure both outputs would be combined on a common scale. Subsequently, the Reclassify tool was used to reclassify these values to a range from 1 to 9 . 


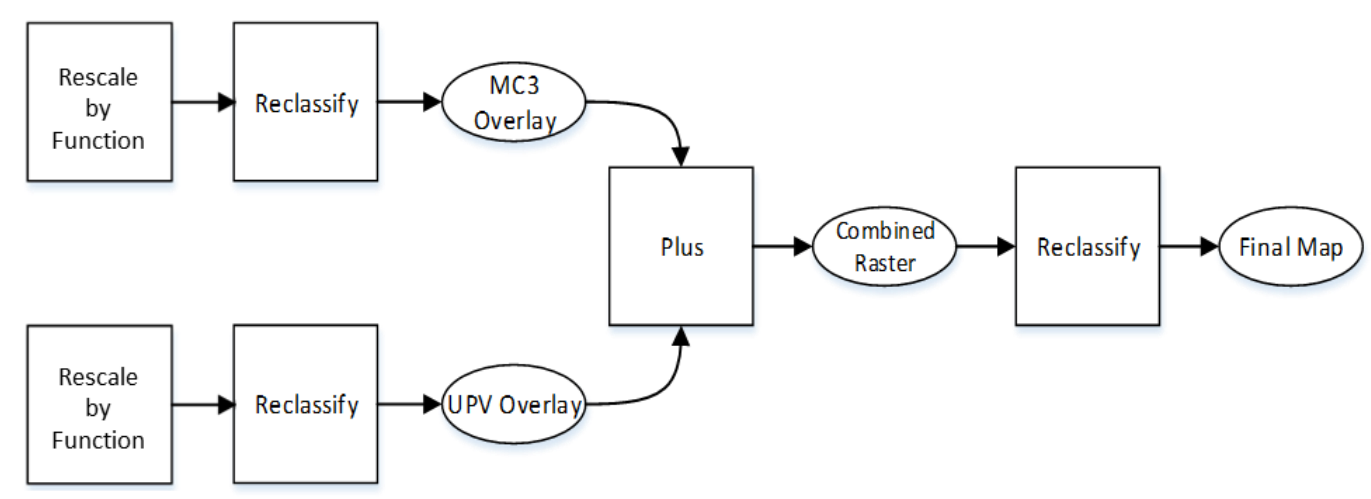

Figure 5-13: Geoprocessing workflow for the combination of UPV and MC3 suitability overlays.

The Plus tool was used to combine MC3 and UPV outputs. The Plus tool works by adding the values of each input raster on a cell by cell basis. The output was then reclassified with a value range from 1 to 9 to produce the suitability map in Figure 5-14. The final map was symbolized from "very low suitability" to "very high suitability."

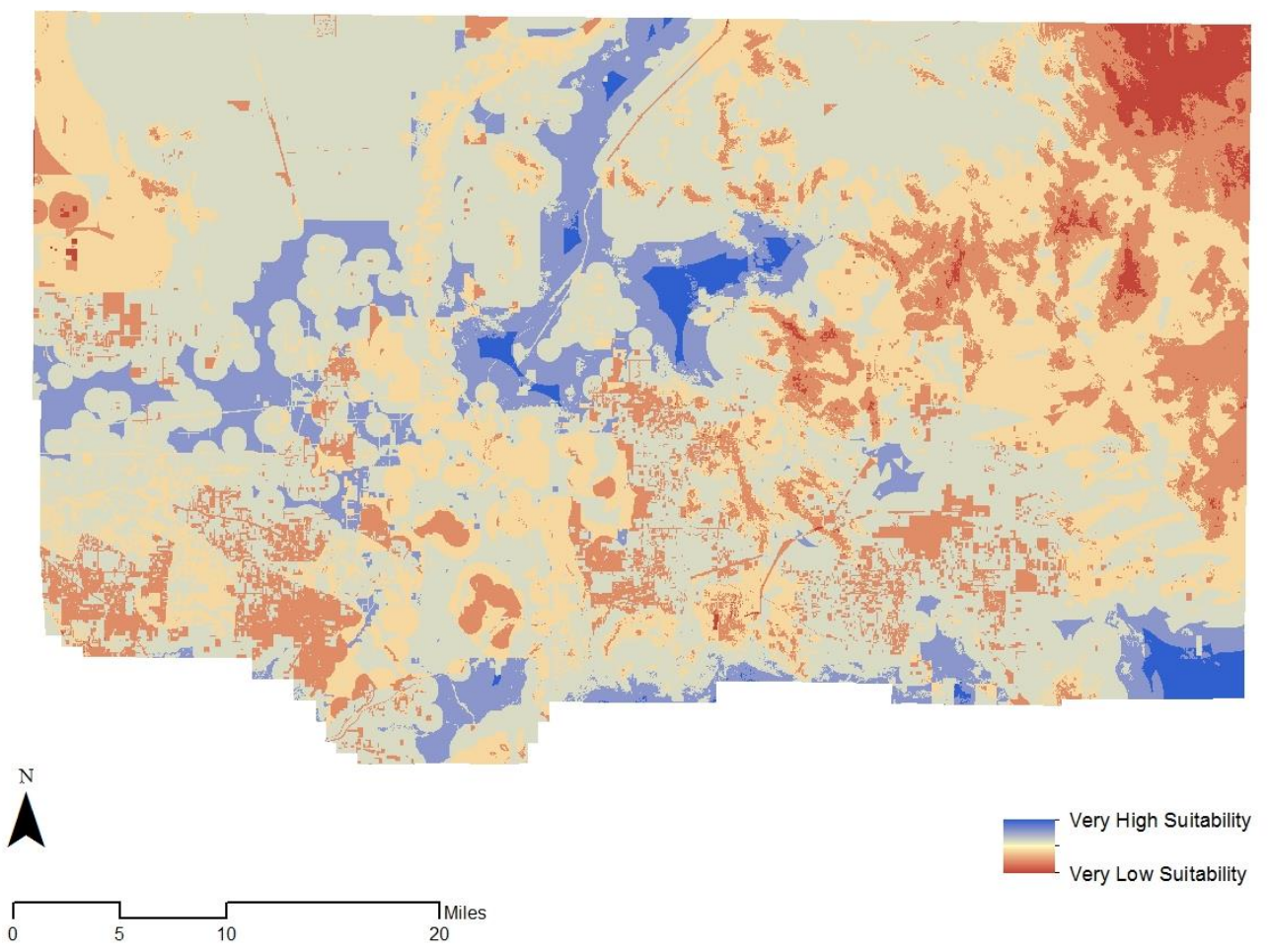

Figure 5-14: Areas in blue are highly suitable for UPV development and acceptable to the MC3. 


\subsection{The Script tool}

The final suitability map in Figure 5-14 was produced with default weight values of 1. Because weights would best be determined by an end user with expertise in UPV suitability. Therefore, the model was exported to PyScripter version 2.7 to allow end user interaction of weight values (Figure 5-15). This was achieved by modifying the script's weighted sum geoprocessing module to a weighted sum table function. The map shown in Figure 5-16 was produced by the tool when transmission line weight was changed to 9. The map illustrates the amplification of the variable's weight.

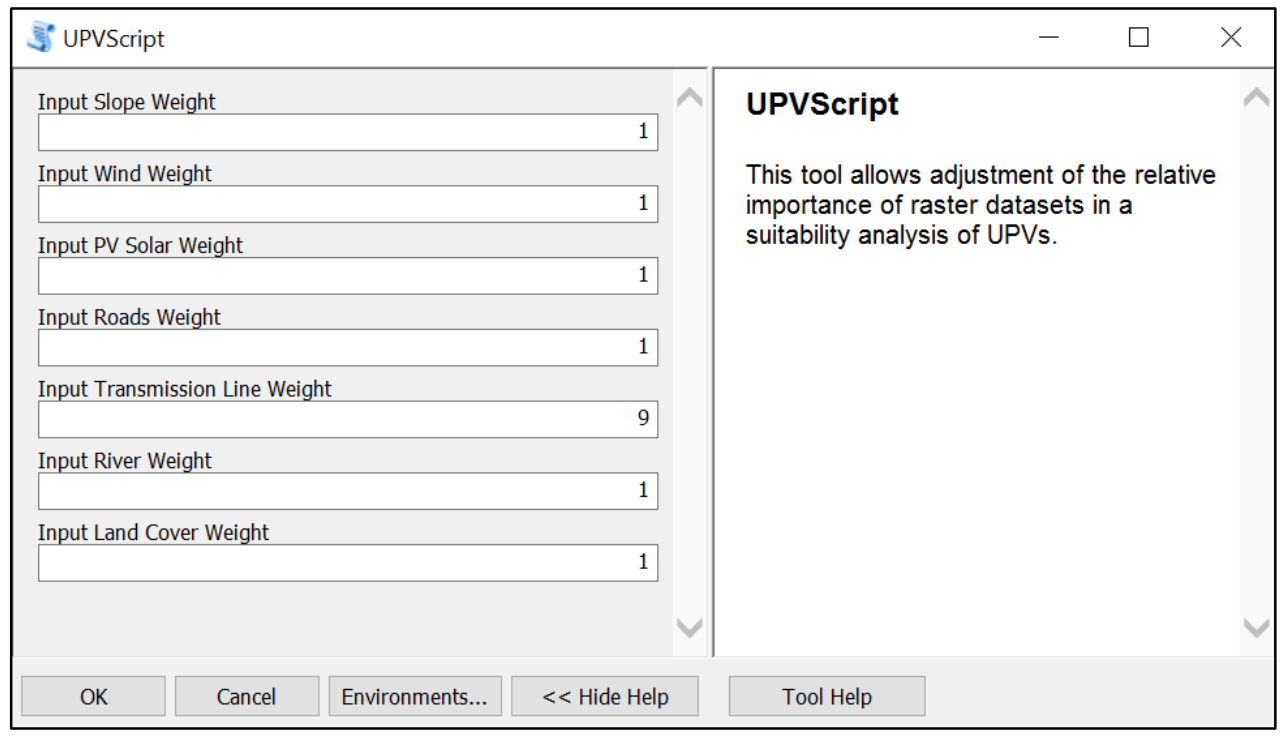

Figure 5-15: Interface allowing the customization of the weight values. 

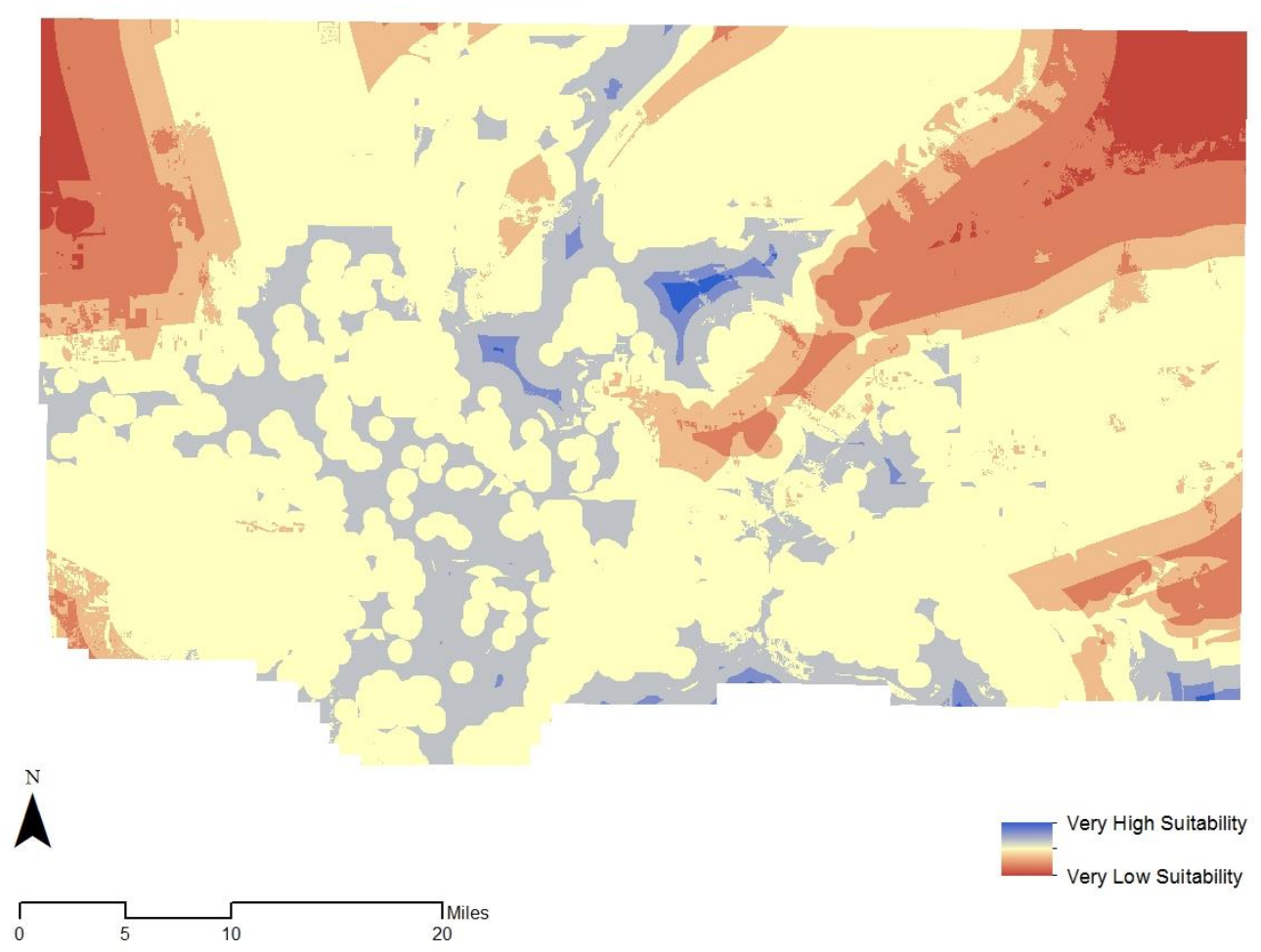

Figure 5-16: Transmission line weight modified to a value of 9.

\subsection{Summary}

This chapter described the implementation of two geoprocessing workflows: UPV suitability and MC3 suitability. The outputs were combined to produce a map showing areas suitable for UPVs. The final output was created by using equal interval as the classification method and weights of 1.0. In addition, the prototype tool was modified with PyScripter to allow the customization of weight values by an end user. 



\section{Chapter 6 - Results and Analysis}

This project set out to provide mapping visualizations of UPV stations for the Mojave Communities Conservation Collaborative (MC3). This was accomplished by providing a prototype tool that allows adjustment of weight values. However, the tool's output (Figure $6-1$ ) is produced with the classification method set at equal interval and weight values set at 1 . The prototype tool will produce different map outputs if weights are modified and classification methods changed by an end user.

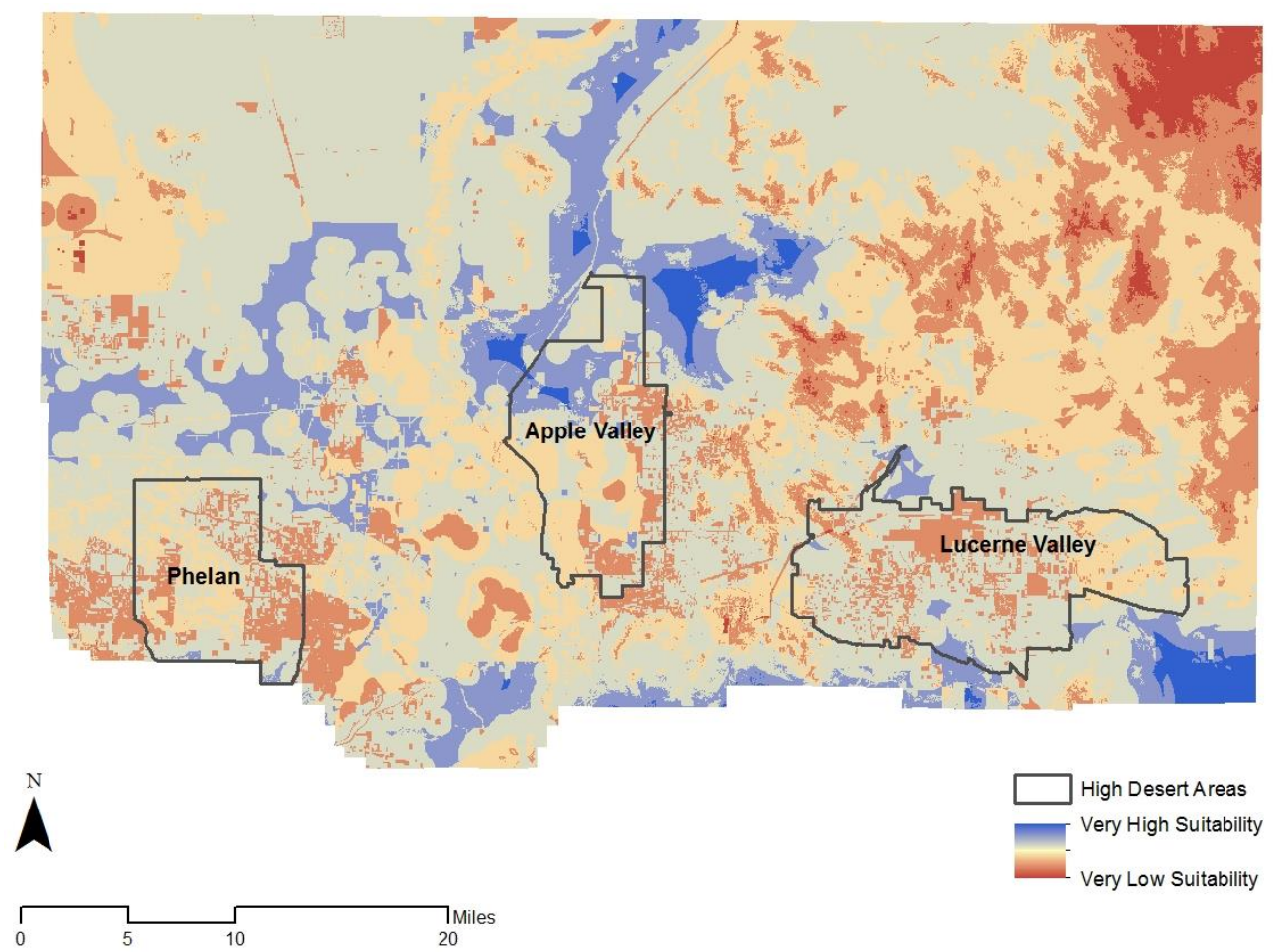

Figure 6-1: Produced with default weight values of 1.

The final suitability map produced by the prototype reveals that when MC3 and UPV suitability are combined, suitable areas for UPV development are dramatically reduced. In Brewer et al., (2015) this finding was also discovered. This means that UPV 
stakeholders and public officials must collaborate with residents in order to come to an agreement.

In order to provide the client with an option to use the prototype tool in future simulations, it was executed with default parameters. However, an additional model was built with Model Builder to produce an output without the need of expert advice. As a result, the MC3 suitability workflow discussed in Chapter 5 was clipped with Development Focused Areas (DFAs) (Figure 6-2). DFAs were generated from the Desert Renewable Energy Conservation Plan (DRECP) preferred alternative land use.

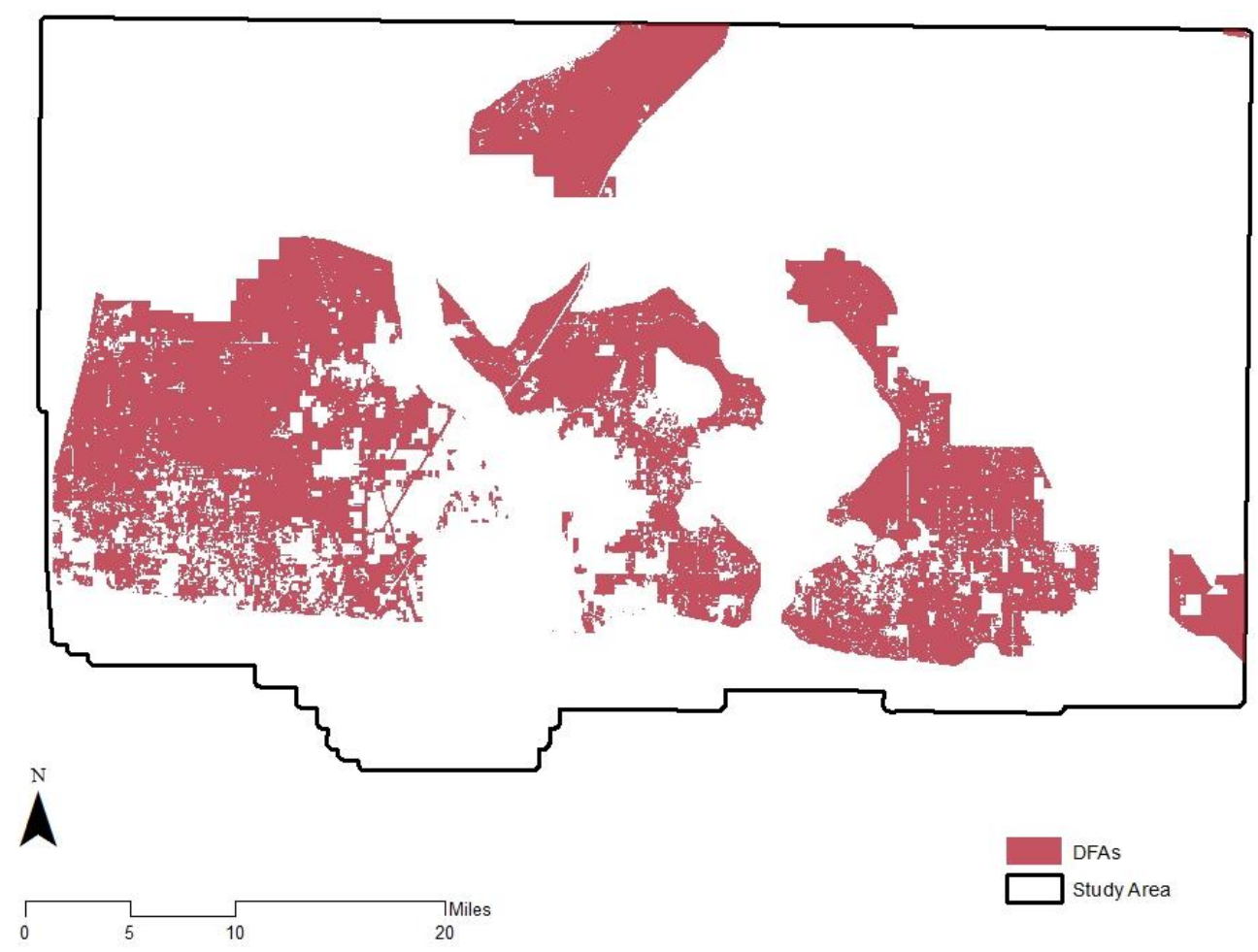

\section{Figure 6-2: Development Focus Areas (DFAs) streamline renewable energy development.}

Figure 6-3 illustrates the geoprocessing workflow that was executed in order to produce a map that combined DFAs with MC3 suitability. Figure 6-4 shows what the 
map looks like when these outputs are combined. The areas in blue are considered highly suitable for UPV development.

The geoprocessing workflow (Figure 6-3) illustrates the MC3 suitability raster clipped with DFAs and subsequently converted into a polygon feature. This allowed the output feature layer to be converted into a shapefile to be uploaded into ArcGIS Online. The web mapping application could then be built.

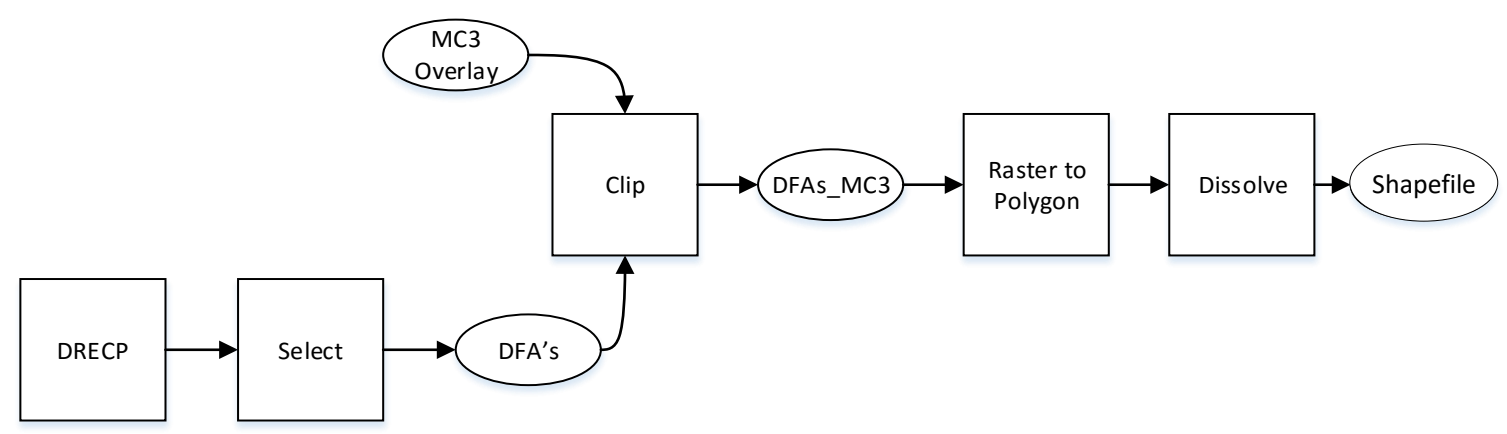

Figure 6-3: Geoprocessing workflow to prepare the feature layer for ArcGIS online. 


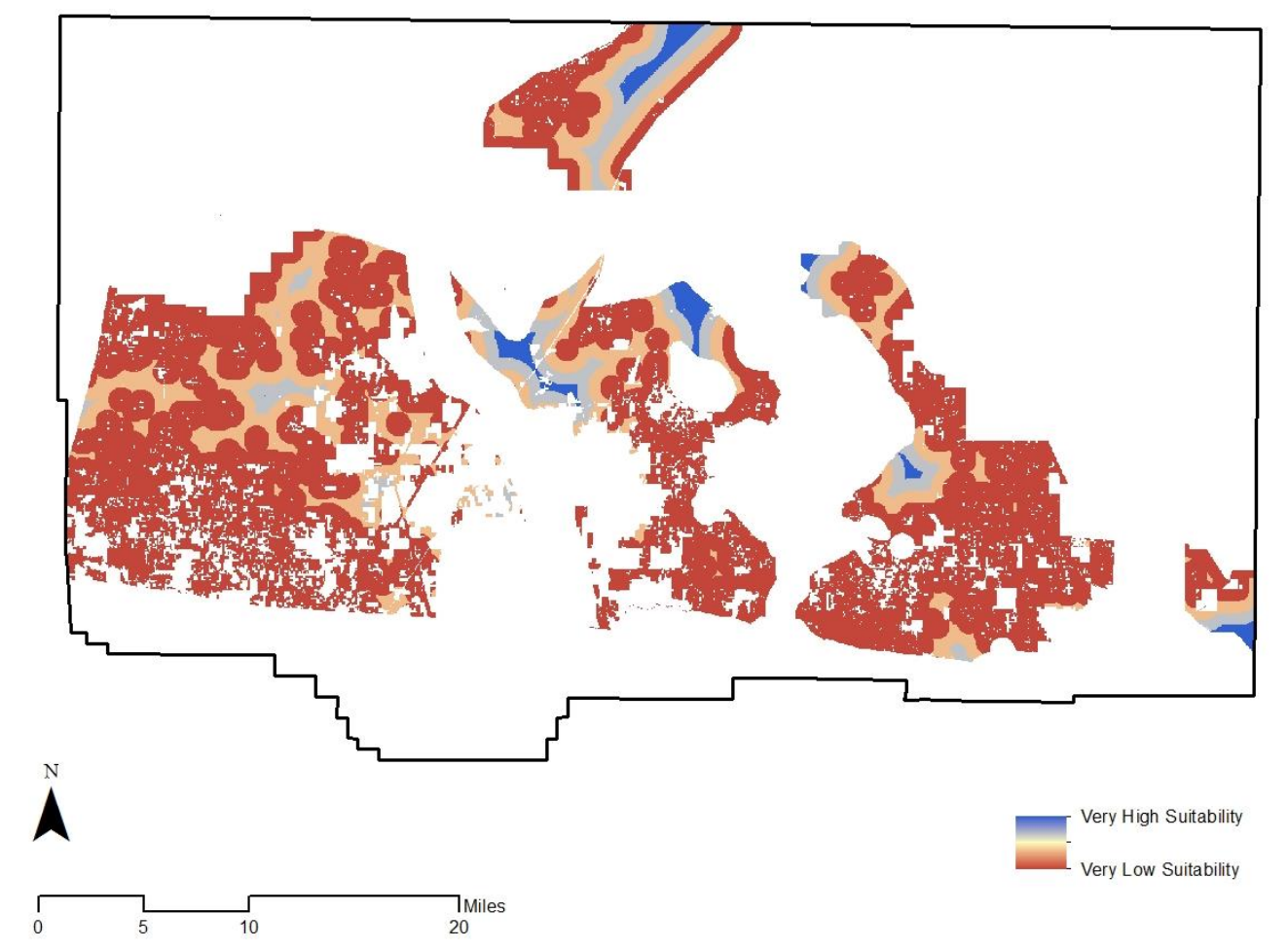

Figure 6-4: Areas in blue are considered suitable for UPV development.

The data illustrated in Figure 6-4 were uploaded to ArcGIS online. The web mapping application allows a comparative analysis of existing DFAs against the output produced by the model (Figure 6-5). DFAs with MC3 suitability were named Social Preference Areas (SPAs). This was done so that a distinction could be made between the two. The web mapping application allows an end user to interact with different layers (Figure 6-6). The web mapping application is intended to demonstrate how DFAs are dramatically reduced when combined with MC3 criteria. 


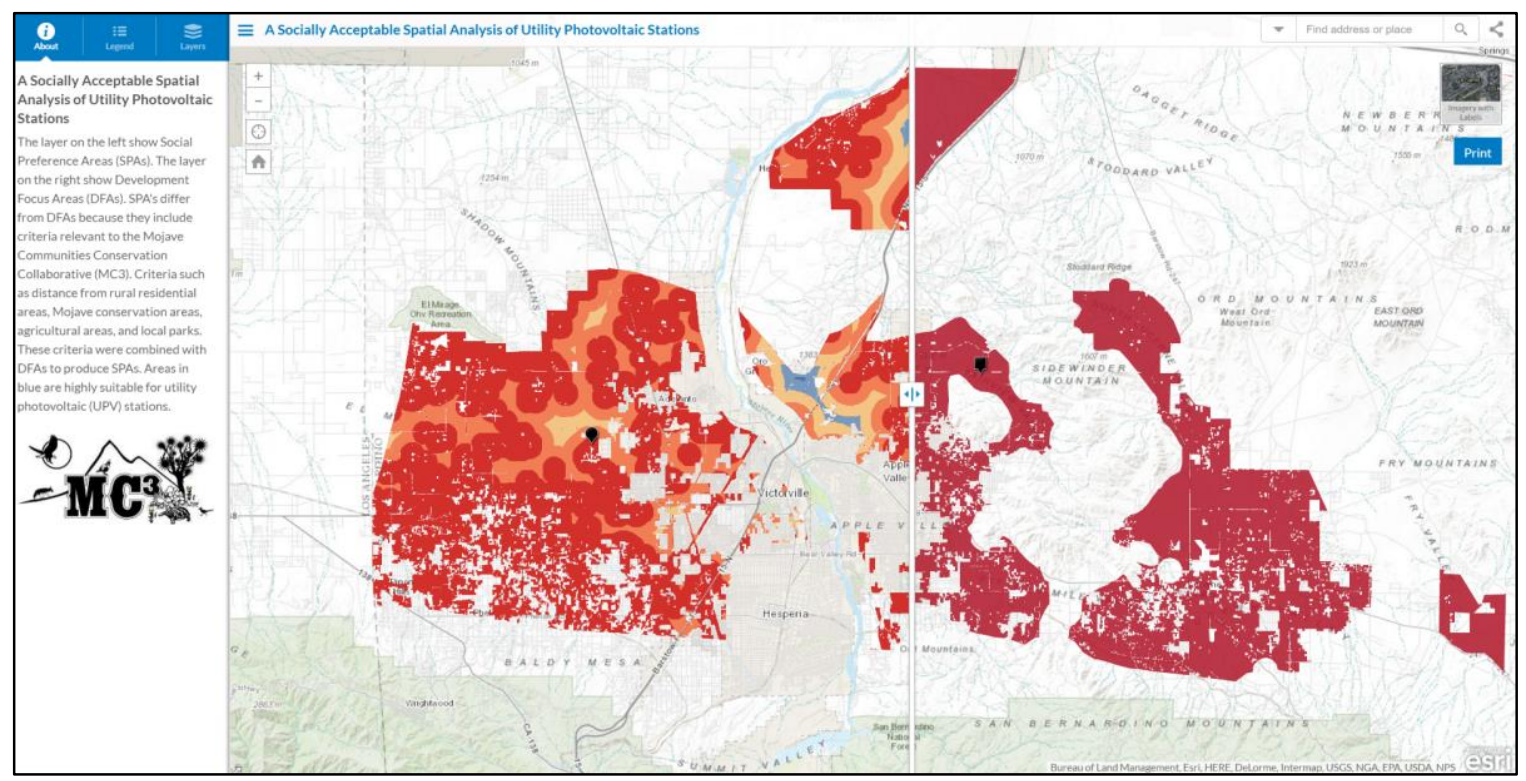

Figure 6-5: A web mapping application was used to allow comparison between SPAs and DFAs.

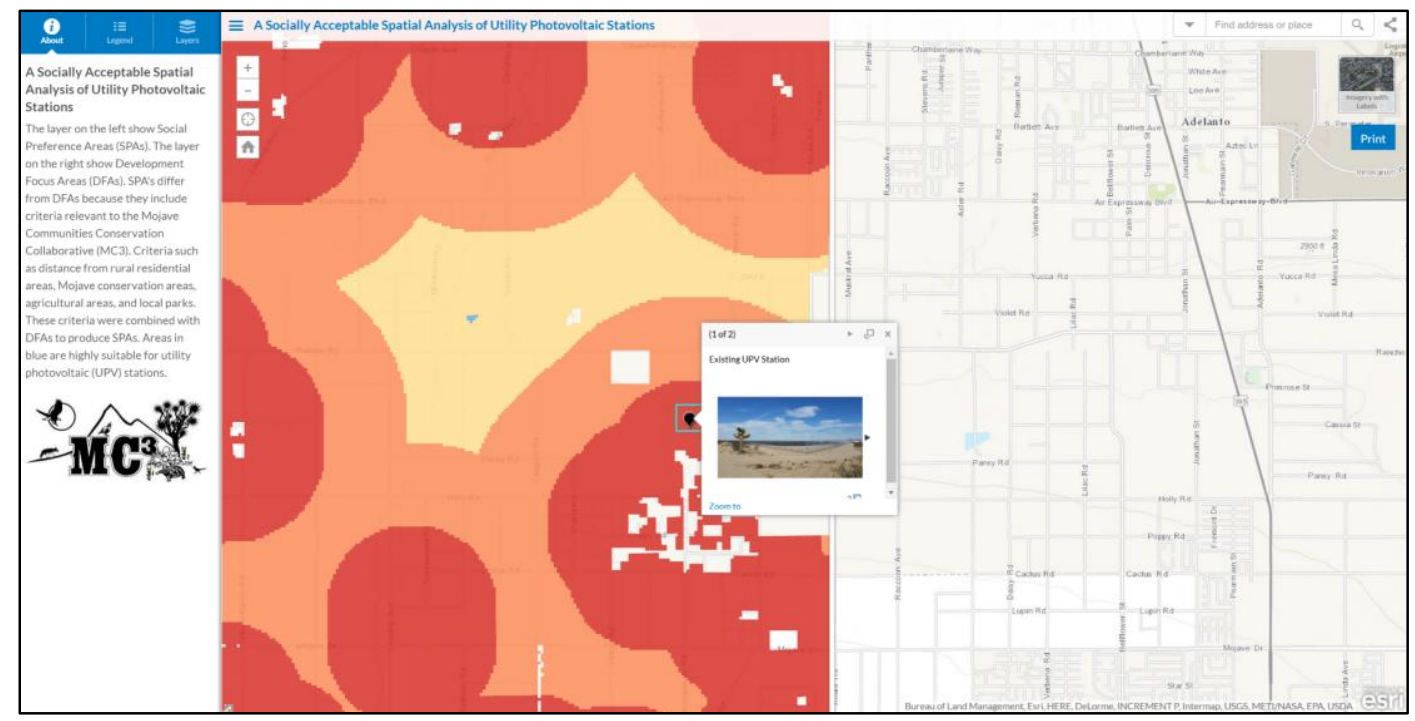

Figure 6-6: Close up of an existing site. Point locations allow one to click and view photographs of the UPV.

An existing UPV location and a targeted site were uploaded into PVMapper. The open source tool generates suitability scores by integrating multiple factors for the given locations. This was important because low scores would indicate accuracy to be 
questionable. However, the overall scores given by PVMapper were 91 for the existing site and 89 for the chosen site, which meant these locations are suitable for UPV development. However, the existing UPV site would not be suitable when compared with the prototype's output because it accounts for rural residential areas. This is a factor that PVMapper does not take into account (Figure 6-7).

\begin{tabular}{|c|c|c|c|c|}
\hline Social Acceptance (6 Tools) & & & UPV Simulation & Existing UPV Site \\
\hline Agriculture Proximity & 5 & 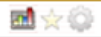 & Error 500 Interna/ Serv ... & Error 500 Internal Sern ... \\
\hline Existing Solar Proximity & 5 & an & There was no existing s 100 & $73.3 \% \pm 4.5 \%$ of peopl \\
\hline Historic Proximity & 5 & 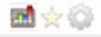 & There was no historic la 100 & There was no historic la 100 \\
\hline Recreational Proximity & 5 & 때숭 & There was no recreatiol 100 & $56.35 \% \pm 6.95 \%$ of per 88 \\
\hline Wetland Proximity & 5 & an & $10.85 \% \pm 2.85 \%$ of pel 54 & $10.85 \% \pm 2.85 \%$ of pei \\
\hline Wildlife Proximity & 5 & 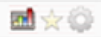 & There was no sensitive 100 & There was no sensitive 100 \\
\hline Social Acceptance (average): & & & \& 91 & $\theta$ \\
\hline
\end{tabular}

\section{Figure 6-7: PV mapper measures social acceptance based on responses from multiple surveys.}

ArcGIS Earth was used to visualize a target site with a 3-D model of an UPV with a $500 \mathrm{KW}$ energy potential. An actual site would be at least doubled this size. The model was downloaded from SketchUp's 3D Warehouse and later modified to the target site.

The result of this model was enhanced visualizations for the MC3 (Figures 6-8 and 6-9).

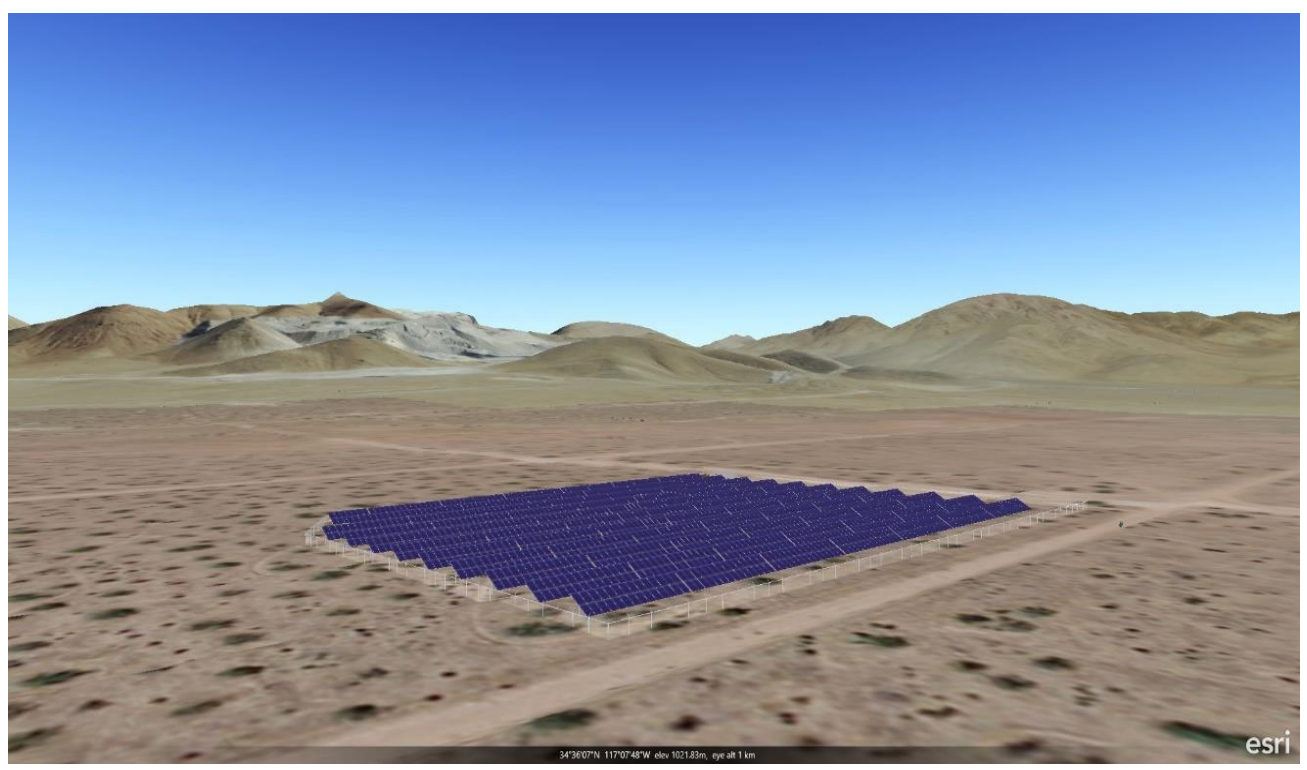


Figure 6-8: View 1 of $500 \mathrm{KW} \mathrm{UPV} \mathrm{site.}$

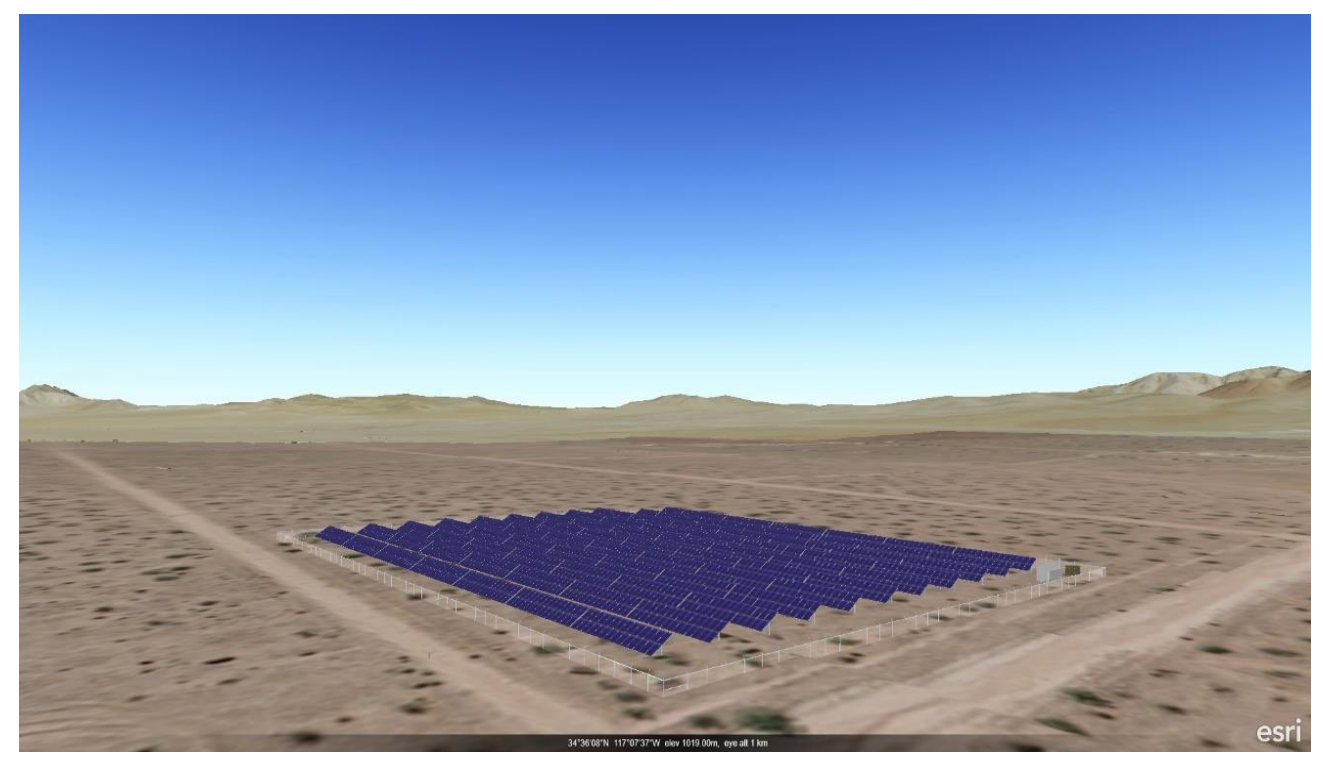

Figure 6-9: View 2 of 500KW UPV site. 


\section{Chapter 7 - Conclusions and Future Work}

The Mojave Communities Conservation Collaborative (MC3) had been dependent on writing letters in opposition to the DRECP draft and other UPV proposals. This was ineffective since stakeholders and public officials usually view letters to be a case of "not-in-my-backyard" or NIMBY. A GIS could therefore provide technical analysis and visualize their concerns through maps, resulting in a more effective opposition. The client, Dr. Bryan Baker, wanted to assist the MC3 by providing them with a GIS that could simulate the impact of UPVs within the area of study. However, in order to provide such analysis, a site suitability study of UPVs needed to be conducted. Research revealed that many suitability studies for UPVs did not include social preferences. In these studies, criteria for UPV placement were focused on economical and physical constraints such as proximity to roads, transmission lines, and flat terrain. However, features important to residents, such as proximity to endangered habitats, recreational areas, and rural residential areas, had largely been excluded. In April of 2015, Brewer and his colleagues attempted to provide a site suitability study of UPVs using social preferences. This project referenced the methodology from a Brewer et al. (2015) case study. Social preferences were accounted for by analyzing UPV proximity from features important to the MC3, such as Mojave conservation areas.

The analysis had to be independent from what the DRECP had produced in its reports because the outputs produced could then be inspected for trustworthiness. Nevertheless, expert advice was needed to adjust parameters. Therefore, this project produced a prototype tool that allows the end user to adjust the relative importance of raster layers in a suitability analysis. A model was provided that combines MC3 criteria 
with DRECP outputs and the results uploaded to ArcGIS Online by means of a web mapping application. This was done to compare the model's outputs with existing Development Focus Areas (DFAs) in the area of study. Dynamic interaction from the application enhanced visualizations for the MC3. This helped the MC3 become more effective in their opposition.

The prototype tool was built so that the client could integrate the tool's outputs in future studies. For example, the tool may be used to define suitable areas for UPVs in order to conduct further analysis, such as a view shed analysis. Google Earth Pro was used in Figure 7-1 to analyze areas that would be visible to a person standing 6 feet tall.

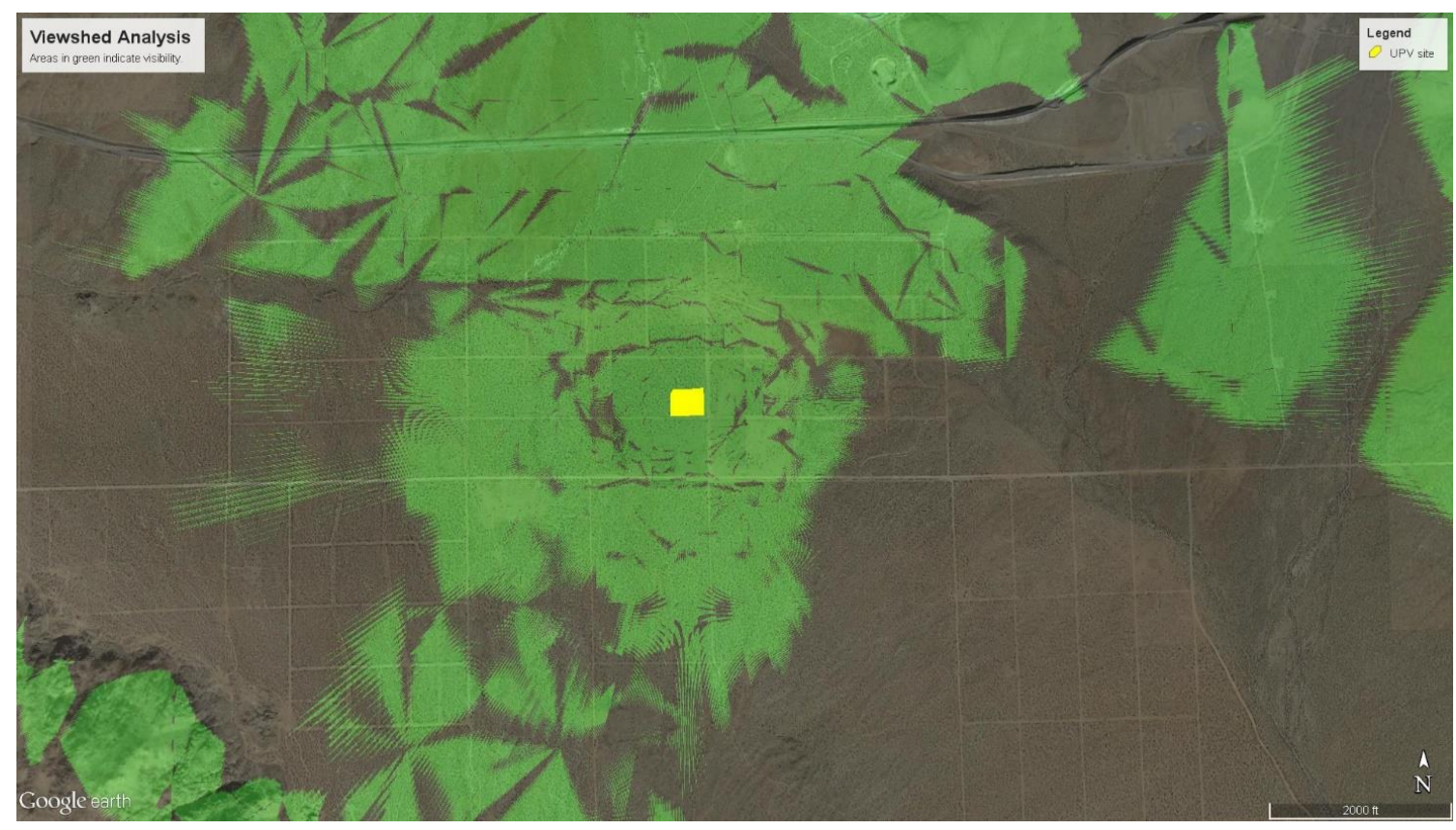

\section{Figure 7-1: An example of possible future work.}

The image shows the UPV site visible from areas in green. This study will help MC3 stakeholders decide if a UPV proposal will negatively alter the desert landscape. This can be an effective method to further increase their success. 
This project achieved its goals and objectives, which were to build a prototype tool, provide a web mapping application, and provide a 3-D model simulation to enhance visualization. In summary, this project was able to provide a way to bring both parties (developers and residents) together while enhancing the effectiveness of the Mojave Communities Conservation Collaborative (MC3). As renewable energy becomes more of an everyday aspect of California, rural residents will be able to enjoy their way of life. 


\section{Works Cited}

Ball, J. (2009). Renewable Energy, Meet the New NIMBYs. Retrieved from http://www.wsj.com/articles/SB125201834987684787

Brewer, J., Ames, D. P., Solan, D., Lee, R., \& Carlisle, J. (2015). Using GIS analytics and social preference data to evaluate utility-scale solar power site suitability. Renewable Energy, 81, 825-836. http://doi.org/10.1016/j.renene.2015.04.017

Davis, T. (2011). Solar farm fails to get support from neighbors. Retrieved from http://tucson.com/business/local/solar-farm-fails-to-get-support-fromneighbors/article_e9b81880-42f0-5fe2-9fad-8c1ec583df11.html

Effat, H. A. (2013). Selection of Potential Sites for Solar Energy Farms in Ismailia Governorate , Egypt using SRTM and Multicriteria Analysis, 2(1), 205-220.

Eriksson, U. (2012). Functional vs Non Functional Requirements. Retrieved September 7, 2015, from http://reqtest.com/requirements-blog/functional-vs-non-functionalrequirements/

Esri. (n.d.). An overview of the geodatabase. Retrieved September 22, 2015, from http://webhelp.esri.com/arcgisserver/9.3/java/index.htm\#geodatabases/an_ove2050156920.htm

Esri. (2012). Understading Euclidean distance analysis.

Esri. (2015). Story Maps. Retrieved from https://storymaps.arcgis.com/en/

Greene, R., Devillers, R., Luther, J. E., \& Eddy, B. G. (2011). GIS-Based MultipleCriteria Decision Analysis. Geography Compass, 5(6), 412-432. http://doi.org/10.1111/j.1749-8198.2011.00431.x

Hott, R., \& Santini, R. (n.d.). Gis-Based Spatial Analysis for Large-Scale Solar Power and Transmission Line Issues : Case Study of Wyoming, U.S.

Janke, J. R. (2010). Multicriteria GIS modeling of wind and solar farms in Colorado. Renewable Energy, 35(10), 2228-2234. http://doi.org/10.1016/j.renene.2010.03.014

Jones, J. H. (2014). Julian residents concerned about proposed solar farm. Retrieved from http://www.sandiegouniontribune.com/news/2014/jan/10/julian-wynola-solar-farmenergy/

Knier, G. (2002). How do Photovoltaics Work? Retrieved from http://science.nasa.gov/science-news/science-at-nasa/2002/solarcells/

Longley, P. A., Goodchild, M. F., Maguire, D. J., \& Rhind, D. W. (2011). Geographic Information Systems \& Science (3rd ed.). John Wiley \& Sons, Inc.

Lucerne Valley Leader. (2015). Renewable Energy: Group writes letters in objection to solar project proposal. Retrieved from http://www.lucernevalleyleader.com/renewable-energy-group-writes-lettersobjection-solar-project-proposal 
Maiorino, A. (2014). Dispel NIMBY Opposition to Solar Projects with a Public Affairs Campaign. Zackin Publications. Retrieved from http://www.solarindustrymag.com/issues/SI1406/FEAT_04_Dispel-NIMBYOpposition-To-Solar-Projects-With-A-Public-Affairs-Campaign.html

McFarland, A. (2015). California first state to generate more than 5\% of electricity from utility-scale solar power. Retrieved September 6, 2015, from http://www.eia.gov/todayinenergy/detail.cfm?id=20492

McHale, M. (2012). Anything can go wrong on a Solar Farm. Retrieved September 16, 2015, from http://www.altenergymag.com/content.php?post_type $=1948$

McKinney, M. (2014). Site Suitability Analysis for a Solar Farm in Watauga County, NC. Journal of Student Research in Environmental Science at Appalachian, 4(1), $62-75$.

Merrouni, A. A., Mezrhab, A. B., \& Mezrhab, A. (2013). CSP sites suitability analysis in the eastern region of Morocco. Energy Procedia, 49, 2270-2279. http://doi.org/10.1016/j.egypro.2014.03.240

Orr, A. B. (2011). Mojave Desert Ecosystem Program Solar and Wind Energy Suitability Modeling Tools. University of Redlands. Retrieved from http://inspire.redlands.edu/gis_gradproj/146/

PV Mapper. (n.d.). Retrieved from http://pvmapper.org/index.html

Roth, S. (2015). Joshua Tree residents cry foul over airport solar plan. Retrieved September 5, 2015, from http://www.desertsun.com/story/news/2015/01/01/joshuatree-nextera-airport-solar/21166567/

Solar Energy Industries Association. (2014). Concentrating Solar Power. Retrieved September 12, 2015, from http://www.seia.org/policy/solartechnology/concentrating-solar-power

Solar Energy Industries Association. (2015). U.S. Installs 6.2 GW of Solar PV in 2014, Up 30\% Over 2013. Retrieved from https://www.seia.org/news/us-installs-62-gwsolar-pv-2014-30-over-2013

Tyson, R. (2012). The new look of NIMBYism. Retrieved September 7, 2015, from http://www.dailyclimate.org/tdc-newsroom/2012/01/green-nimbyism 